Atmos. Chem. Phys., 13, 11819-11838, 2013

www.atmos-chem-phys.net/13/11819/2013/

doi:10.5194/acp-13-11819-2013

(c) Author(s) 2013. CC Attribution 3.0 License.

\title{
Evaluating global emission inventories of biogenic bromocarbons
}

\author{
R. Hossaini ${ }^{1}$, H. Mantle ${ }^{1}$, M. P. Chipperfield ${ }^{1}$, S. A. Montzka ${ }^{2}$, P. Hamer ${ }^{3}$, F. Ziska ${ }^{4}$, B. Quack ${ }^{4}$, K. Krüger ${ }^{4, *}$, S.

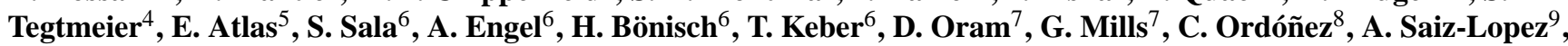 \\ N. Warwick ${ }^{10}$, Q. Liang ${ }^{11}$, W. Feng ${ }^{1}$, F. Moore ${ }^{2}$, B. R. Miller ${ }^{2}$, V. Marécal ${ }^{3}$, N. A. D. Richards ${ }^{1}$, M. Dorf ${ }^{12}$, and K. \\ Pfeilsticker $^{12}$ \\ ${ }^{1}$ Institute for Climate and Atmospheric Science (ICAS), School of Earth and Environment, University of Leeds, Leeds, UK \\ ${ }^{2}$ National Oceanic and Atmospheric Administration, Boulder, USA \\ ${ }^{4}$ GEOMAR Helmholtz Centre for Ocean Research Kiel, Kiel, Germany \\ ${ }^{5}$ Rosenstiel School of Marine and Atmospheric Science, University of Miami, Miami, USA \\ ${ }^{6}$ Institute for Atmospheric and Environmental Sciences, Universität Frankfurt/Main, Germany \\ ${ }^{7}$ School of Environmental Sciences, University of East Anglia, Norwich, UK \\ ${ }^{8}$ Met Office, Exeter, UK \\ ${ }^{9}$ Atmospheric Chemistry and Climate Group, Institute for Physical Chemistry Rocasolano, CSIC, Madrid, Spain \\ ${ }^{10}$ National Centre for Atmospheric Science (NCAS), University of Cambridge, Cambridge, UK \\ ${ }^{11}$ Universities Space Research Association, GESTAR, Columbia, Maryland, USA \\ ${ }^{12}$ Institute for Environmental Physics, University of Heidelberg, Heidelberg, Germany \\ * now at: Department of Geosciences, University of Oslo, Oslo, Norway
}

Correspondence to: R. Hossaini (r.hossaini@see.leeds.ac.uk)

Received: 9 April 2013 - Published in Atmos. Chem. Phys. Discuss.: 14 May 2013

Revised: 18 September 2013 - Accepted: 4 November 2013 - Published: 6 December 2013

\begin{abstract}
Emissions of halogenated very short-lived substances (VSLS) are poorly constrained. However, their inclusion in global models is required to simulate a realistic inorganic bromine $\left(\mathrm{Br}_{\mathrm{y}}\right)$ loading in both the troposphere, where bromine chemistry perturbs global oxidising capacity, and in the stratosphere, where it is a major sink for ozone $\left(\mathrm{O}_{3}\right)$. We have performed simulations using a 3-D chemical transport model (CTM) including three top-down and a single bottom-up derived emission inventory of the major brominated VSLS bromoform $\left(\mathrm{CHBr}_{3}\right)$ and dibromomethane $\left(\mathrm{CH}_{2} \mathrm{Br}_{2}\right)$. We perform the first concerted evaluation of these inventories, comparing both the magnitude and spatial distribution of emissions. For a quantitative evaluation of each inventory, model output is compared with independent long-term observations at National Oceanic and Atmospheric Administration (NOAA) ground-based stations and with aircraft observations made during the NSF (National Science Foundation) HIAPER Pole-to-Pole Observations (HIPPO) project. For $\mathrm{CHBr}_{3}$, the mean absolute deviation between model and surface observation ranges from $0.22(38 \%)$ to $0.78(115 \%)$ parts per trillion (ppt) in the trop-
\end{abstract}

ics, depending on emission inventory. For $\mathrm{CH}_{2} \mathrm{Br}_{2}$, the range is $0.17(24 \%)$ to $1.25(167 \%)$ ppt. We also use aircraft observations made during the 2011 Stratospheric Ozone: Halogen Impacts in a Varying Atmosphere (SHIVA) campaign, in the tropical western Pacific. Here, the performance of the various inventories also varies significantly, but overall the CTM is able to reproduce observed $\mathrm{CHBr}_{3}$ well in the free troposphere using an inventory based on observed sea-to-air fluxes. Finally, we identify the range of uncertainty associated with these VSLS emission inventories on stratospheric bromine loading due to VSLS $\left(\mathrm{Br}_{\mathrm{y}}^{\mathrm{VSLS}}\right)$. Our simulations show $\mathrm{Br}_{\mathrm{y}}^{\mathrm{VSLS}}$ ranges from $\sim 4.0$ to 8.0 ppt depending on the inventory. We report an optimised estimate at the lower end of this range $(\sim 4 \mathrm{ppt})$ based on combining the $\mathrm{CHBr}_{3}$ and $\mathrm{CH}_{2} \mathrm{Br}_{2}$ inventories which give best agreement with the compilation of observations in the tropics. 


\section{Introduction}

On regional to global scales, bromine $(\mathrm{Br})$ chemistry plays an important role in atmospheric composition. In the stratosphere, through coupling with analogous chlorine radicals, active bromine $\left(\mathrm{Br}_{\mathrm{x}}=\mathrm{Br}+\mathrm{BrO}\right)$ takes part in catalytic cycles (e.g. $\mathrm{BrO}-\mathrm{ClO})$ which cause large seasonal ozone $\left(\mathrm{O}_{3}\right)$ loss during polar spring (e.g. Solomon, 1999, and references therein). At midlatitudes, a cycle involving hydroperoxyl radicals $\left(\mathrm{HO}_{2}\right)$ (e.g. Lary, 1996) is also significant, particularly during periods of elevated stratospheric aerosol when heterogeneous halogen activation is enhanced (Salawitch et al., 2005; Feng et al., 2007). Reduced column $\mathrm{O}_{3}$ increases the transmission of potentially harmful ultraviolet (UV) radiation to the surface, in addition to impacting surface temperature and climate both directly and indirectly (e.g. WMO, 2011, and references therein).

In the troposphere, where understanding of halogen impacts is evolving rapidly (e.g. Saiz-Lopez and von Glasow, 2012), Br-mediated $\mathrm{O}_{3}$ loss is also significant (von Glasow et al., 2004; Yang et al., 2005), such as in the marine boundary layer (MBL) (e.g. Read et al., 2008) where biogenic emissions of halogenated species can be large (e.g. Carpenter and Liss, 2000; Quack and Wallace, 2003). Modelling work has also highlighted the importance of halogen-driven $\mathrm{O}_{3}$ loss in the mid-upper troposphere (Saiz-Lopez et al., 2012). Through reactions involving $\mathrm{HO}_{\mathrm{x}}\left(\mathrm{OH}\right.$ and $\left.\mathrm{HO}_{2}\right)$ and $\mathrm{NO}_{\mathrm{x}}$ ( $\mathrm{NO}$ and $\mathrm{NO}_{2}$ ), bromine chemistry may indirectly perturb oxidising capacity and thus impact the lifetime of greenhouse gases (GHGs) such as methane $\left(\mathrm{CH}_{4}\right)$ (e.g. Lary and Toumi, 1997). Bromine chemistry may also impact other climaterelevant species; e.g. bromine monoxide $(\mathrm{BrO})$ is a significant sink for dimethyl sulfide (DMS) - a precursor for cloud condensation nuclei (CCN) (Breider et al., 2010).

Sources of organic bromine include anthropogenic emissions of long-lived halons (e.g. $\mathrm{CBrF}_{3}$, Halon 1301) and also methyl bromide $\left(\mathrm{CH}_{3} \mathrm{Br}\right)$, whose emissions are mostly biogenic $(>70 \%)$ (e.g. WMO, 2011). As their production is regulated under the Montreal Protocol (and amendments), the total tropospheric bromine burden from these gases is now declining, from a peak observed towards the end of the 20th century (Montzka et al., 2003). Given their long tropospheric lifetimes, these gases are a relatively minor source of total inorganic bromine $\left(\mathrm{Br}_{\mathrm{y}}\right)$ below the tropopause. However, in the stratosphere they account for $\sim 75 \%$ of the total $\mathrm{Br}_{\mathrm{y}}$ budget. The remainder is thought to arise from so-called very short-lived substances (VSLS) of predominately natural oceanic origin (e.g. Sturges et al., 2000; Pfeilsticker et al., 2000). In recent years, both observational (e.g. Sioris et al., 2006; Dorf et al., 2006, 2008; Salawitch et al., 2010; Brinckmann et al., 2012) and modelling (e.g. Schofield et al., 2011; Hossaini et al., 2012b; Tegtmeier et al., 2012; Aschmann and Sinnhuber, 2013) studies have constrained their contribution to stratospheric $\mathrm{Br}_{\mathrm{y}}\left(\mathrm{Br}_{\mathrm{y}}^{\mathrm{VSLS}}\right)$ - currently estimated at $1-8$ parts per trillion (ppt) (Montzka and Reimann, 2011).
The most abundant Br-containing VSLS are bromoform $\left(\mathrm{CHBr}_{3}\right)$ and dibromomethane $\left(\mathrm{CH}_{2} \mathrm{Br}_{2}\right)$ with mean MBL mixing ratios of $\sim 1.1$ and $1.5 \mathrm{ppt}$. As their nominal surface lifetimes are short $(\sim 26$ and 120 days, assuming $[\mathrm{OH}]=$ $1 \times 10^{6}$ molecules $\mathrm{cm}^{-3}$ and a global/seasonal mean photolysis rate), and their emissions exhibit significant spatial and temporal inhomogeneity, tropospheric gradients can be large (Montzka and Reimann, 2011). Localised hot-spots, where emissions are relatively strong, have been identified; for example Mace Head (Ireland) (e.g. Carpenter et al., 2005). At present, the total global source strength of these VSLS are poorly constrained and range from 430 to $1400 \mathrm{Gg} \mathrm{Br} \mathrm{yr}^{-1}$ and $57-280 \mathrm{Gg} \mathrm{Bryr}^{-1}$ for $\mathrm{CHBr}_{3}$ and $\mathrm{CH}_{2} \mathrm{Br}_{2}$ (Montzka and Reimann, 2011). For global-scale models, a sound treatment of the magnitude and spatial distribution of VSLS emissions is required in order to simulate a reasonable $\mathrm{Br}_{\mathrm{y}}$ budget in both the troposphere and the stratosphere. As recent chemistry-climate model (CCM) studies suggest $\mathrm{Br}_{\mathrm{y}}^{\mathrm{VSLS}}$ in the lower stratosphere may increase in response to climate change (Dessens et al., 2009; Hossaini et al., 2012a), validation of VSLS emission inventories is particularly important.

Here, we use a three-dimensional (3-D) chemical transport model (CTM) to investigate global $\mathrm{CHBr}_{3}$ and $\mathrm{CH}_{2} \mathrm{Br}_{2}$ emission inventories. We perform the first concerted evaluation of three top-down and a single bottom-up derived inventory using a combination of long-term ground-based observations and aircraft observations. A case study for the period of the 2011 Stratospheric Ozone: Halogen Impacts in a Varying Atmosphere (SHIVA) campaign, in which aircraft VSLS observations were obtained over the poorly sampled tropical western Pacific, is also performed. Finally, we update our previous model estimate of stratospheric $\mathrm{Br}_{\mathrm{y}}^{\mathrm{VSLS}}$ based on these new emission data sets. Section 2 provides a description of the CTM and the emission inventories. Section 3 contains a quantitative comparison of the CTM with groundbased data. Section 4 contains a comparison of the CTM with observations from the recent HIAPER Pole-to-Pole Observation (HIPPO) campaigns. Section 5 highlights results from the SHIVA western Pacific case study. Section 6 examines the sensitivity of $\mathrm{Br}_{\mathrm{y}}^{\mathrm{VSLS}}$ to emission inventories. A summary and conclusions are given in Sect. 7.

\section{Model and experiments}

TOMCAT is a global 3-D CTM described in Chipperfield (2006). The CTM runs offline and uses prescribed $6 \mathrm{~h}$ wind, temperature and humidity fields from the European Centre for Medium-Range Weather Forecasts (ECMWF) ERA Interim reanalysis. The CTM includes a treatment of convection, described in Stockwell and Chipperfield (1999) and further validated in Feng et al. (2011), based on the mass flux scheme of Tiedtke (1989). Vertical winds are diagnosed from divergence. In the boundary layer, turbulent mixing follows the non-local scheme of Holtslag and Boville (1993). For 
tracer advection, the CTM uses the conservation of 2nd-order moments scheme of Prather (1986). The CTM was run with a resolution of $\sim 2.8^{\circ}$ longitude $\times \sim 2.8^{\circ}$ latitude and with 60 hybrid sigma-pressure $(\sigma-p)$ levels (surface to $\sim 60 \mathrm{~km}$ ).

The CTM configuration here is similar to that of Hossaini et al. (2012b) and includes 5 brominated very short-lived (VSL) source gases (SGs): $\mathrm{CHBr}_{3}, \mathrm{CH}_{2} \mathrm{Br}_{2}$, dibromochloromethane $\left(\mathrm{CHBr}_{2} \mathrm{Cl}\right)$, bromodichloromethane $\left(\mathrm{CHBrCl}_{2}\right)$ and bromochloromethane $\left(\mathrm{CH}_{2} \mathrm{BrCl}\right)$. Loss of these SGs occurs via oxidation with the hydroxyl radical $(\mathrm{OH})$ or by photolysis, calculated using the recommended rate constants/absorption cross-section data of Sander et al. (2011). For simulations here, the CTM used a prescribed monthly mean $\mathrm{OH}$ field which was used in TransCom- $\mathrm{CH}_{4}$ (Patra et al., 2011) and produced reasonable simulations of methyl chloroform $\left(\mathrm{CH}_{3} \mathrm{CCl}_{3}\right)$ and $\mathrm{CH}_{4}$.

\subsection{Biogenic emissions from the ocean}

Given the significant uncertainty in global VSLS emissions, TOMCAT was run for the period 1 January 1997 to 31 December 2011 with 4 previously published oceanic $\mathrm{CHBr}_{3}$ and $\mathrm{CH}_{2} \mathrm{Br}_{2}$ emission inventories. Run $S_{\text {Liang }}$ used the top-down emission fluxes of Liang et al. (2010) (hereafter "Liang2010 "). Run $S_{\text {Warwick }}$ used the top-down estimates described in Warwick et al. (2006) and updated in Pyle et al. (2011) (hereafter "Warwick-2011"). Run $S_{\text {Ordonez }}$ used the top-down estimates of Ordóñez et al. (2012) (“Ordóñez-2012”). Finally, run $S_{\text {Ziska }}$ used the bottom-up emission fluxes proposed by Ziska et al. (2013) (“Ziska-2013”). The global total emissions for each source gas under each scenario is given in Table 1 .

The top-down inventories described below rely on aircraft observations of $\mathrm{CHBr}_{3}$ and $\mathrm{CH}_{2} \mathrm{Br}_{2}$ to constrain surface fluxes using a global model. Assumptions regarding the latitudinal distribution and the relative importance of open ocean versus coastal emissions are made and vary between inventories. Therefore, some of the most significant uncertainty in the top-down approach is due to the lack of available $\mathrm{CHBr}_{3}$ and $\mathrm{CH}_{2} \mathrm{Br}_{2}$ observations in the free troposphere over certain regions and due to the lack of understanding of emission distribution. An iterative modelling approach is used whereby the magnitude of emissions within a given latitude band is adjusted, in a sequential set of simulations, to yield the optimised agreement with observations. Model parameters, such as coarse horizontal resolution, may add further uncertainty as strong local emissions, such as those from coastal regions, are smeared over a relatively large grid box. The use of observations representative of the background tropospheric $\mathrm{CHBr}_{3}$ and $\mathrm{CH}_{2} \mathrm{Br}_{2}$ loading may also lead to an under-representation of particularly strong local emissions or hot-spots in the top-down approach.

The Warwick-2011 scenario is a top-down estimate based on the original work of Warwick et al. (2006). Aircraft observations of $\mathrm{CHBr}_{3}$ and $\mathrm{CH}_{2} \mathrm{Br}_{2}$, collected during the 1999
Table 1. Summary of $14 \mathrm{yr}$ CTM runs and the global total source strength ( $\mathrm{Gg}$ source gas $\mathrm{yr}^{-1}$ ) of $\mathrm{CHBr}_{3}$ and $\mathrm{CH}_{2} \mathrm{Br}_{2}$.

\begin{tabular}{lllll}
\hline Run & Scenario & Derivation & $\mathrm{CHBr}_{3}$ & $\mathrm{CH}_{2} \mathrm{Br}_{2}$ \\
\hline$S_{\text {Liang }}$ & Liang-2010 & Top-down & 450 & 62 \\
$S_{\text {Warwick }}$ & Warwick-2011 & Top-down & 380 & 113 \\
$S_{\text {Ordonez }}$ & Ordóñez-2012 & Top-down & 533 & 67 \\
$S_{\text {Ziska }}$ & Ziska-2013 & Bottom-up & 183 & 64 \\
\hline
\end{tabular}

National Aeronautics and Space Administration (NASA) Pacific Exploratory Mission (PEM) Tropics B, were used to constrain surface emissions. The updated scenario used here is based on scenario 5 outlined in Warwick et al. (2006), however South-east Asian $\mathrm{CHBr}_{3}$ emissions have been scaled down to give agreement with surface observations collected at Danum Valley, Borneo. This updated scenario is further described in Pyle et al. (2011).

The Liang-2010 scenario is also a model top-down estimate constrained by aircraft observations. These observations were mostly concentrated around the Pacific and North America between 1996 and 2008 and include the following campaigns: PEM-Tropics, TRACE-P, INTEX, TC4, ARCTAS, STRAT, Pre-AVE and AVE (Liang et al., 2010). The emissions were formulated using a baseline scenario from Warwick et al. (2006), which was adjusted in both magnitude and location, so that modelled $\mathrm{CHBr}_{3}$ and $\mathrm{CH}_{2} \mathrm{Br}_{2}$ gave good agreement with observations in the mid-troposphere, and the observed vertical gradient was well represented. The spatial distribution of emissions is assumed to be equal for $\mathrm{CHBr}_{3}$ and $\mathrm{CH}_{2} \mathrm{Br}_{2}$.

The Ordónez-2012 scenario is the third top-down estimate. It is formulated using the same aircraft observations as Liang-2010 but also includes those obtained during the NASA POLARIS and SOLVE missions. This scenario is relatively sophisticated as, in the tropics $\left( \pm 20^{\circ}\right)$, VSLS emissions are weighted towards the concentration of chlorophyll $a$ (chl $a$ ); a potential proxy for oceanic bioproductivity. A monthly-varying satellite chl $a$ climatology was used which allows some seasonality in the magnitude of the $\mathrm{CHBr}_{3}$ and $\mathrm{CH}_{2} \mathrm{Br}_{2}$ emission fields. This is the only inventory to consider such seasonality. Outside of tropical latitudes the sea-air flux is constant with coastal emissions assumed to be a factor of 2.5 larger than the open ocean.

Finally, the Ziska-2013 scenario is a bottom-up estimate of emissions. Based on data of the HalOcAt database project (https://halocat.geomar.de/), global surface marine and atmospheric concentration maps of $\mathrm{CHBr}_{3}$ and $\mathrm{CH}_{2} \mathrm{Br}_{2}$ (and $\mathrm{CH}_{3} \mathrm{I}$ ) were calculated in order to derive global sea-to-air flux estimates. The available in situ measurements were classified according to current knowledge about the distribution and possible sources of each compound, as well as the physical and biogeochemical characteristics of ocean and atmosphere. Missing $1^{\circ} \times 1^{\circ}$ grid values were extrapolated with 


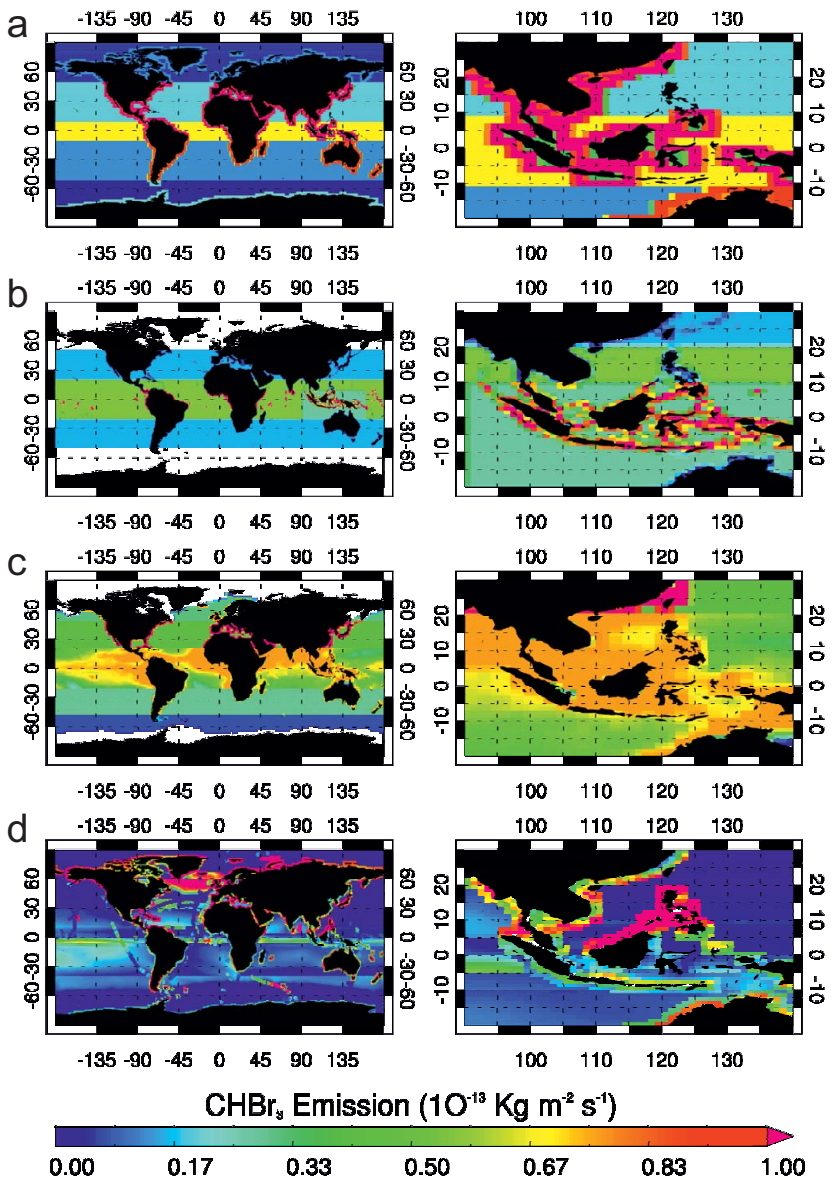

Fig. 1. Bromoform emission field $\left(10^{-13} \mathrm{~kg} \mathrm{~m}^{-2} \mathrm{~s}^{-1}\right)$ on $1^{\circ} \times 1^{\circ}$ grid for global (left) and western Pacific (right) regions. Emissions from the (a) Liang-2010, (b) Warwick-2011, (c) Ordóñez-2012 and (d) Ziska-2013 scenarios.

the ordinary least square (OLS) regression technique depending on longitude and latitude. The OLS method includes outliers and thus represents the spread and variable concentration distribution well. Based on the generated marine and atmospheric surface concentration maps, global climatological emission maps were calculated with a commonly used sea-to-air flux parameterisation. This applied highly temporal $(6 \mathrm{~h})$ resolved wind speed, sea surface temperature, salinity and pressure data (Ziska et al., 2013).

Global emission maps for $\mathrm{CHBr}_{3}$ and $\mathrm{CH}_{2} \mathrm{Br}_{2}$ are shown in Figs. 1 and 2, respectively. All scenarios differ significantly over the tropical western Pacific - an important region for the troposphere-stratosphere transport of VSLS (e.g. Aschmann et al., 2009), where observations of these species are limited. The latitudinal-dependence of emissions is shown in Fig. 3. For $\mathrm{CHBr}_{3}$, significant variation between the top-down derived estimates (Warwick-2011, Liang-2010, Ordóñez-2012) and the bottom-up estimate (Ziska-2013) is apparent - particularly in the tropics $\left( \pm 20^{\circ}\right)$ and at high latitudes $\left(>60^{\circ}\right)$ in the Northern Hemisphere (NH). For $\mathrm{CH}_{2} \mathrm{Br}_{2}$,
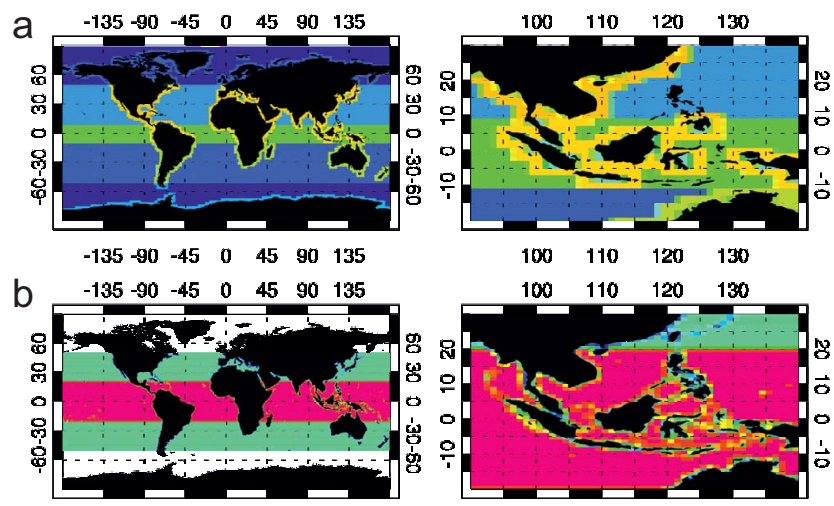

$\begin{array}{llll}100 & 110 & 120 & 130\end{array}$

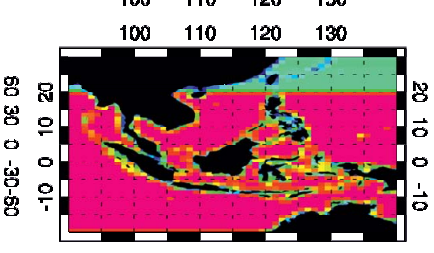

$\begin{array}{lllllll}-135 & -90 & -45 & 0 & 45 & 90 & 135\end{array}$
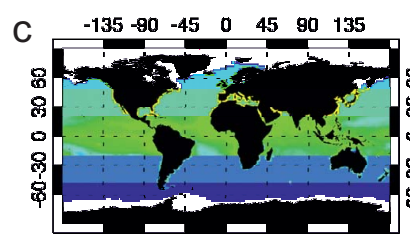

$\begin{array}{lllllll}-135 & -90 & -45 & 0 & 45 & 90 & 135\end{array}$
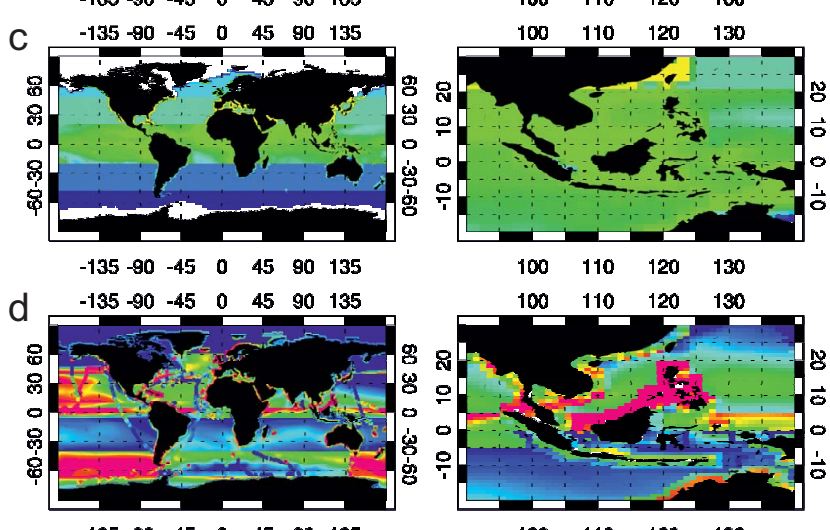

$\begin{array}{lllllll}-135 & -90 & -45 & 0 & 45 & 90 & 135\end{array}$

$\begin{array}{llll}100 & 110 & 120 & 130\end{array}$

$\mathrm{CH}_{2} \mathrm{Br}_{2}$ Emission $\left(1 \mathrm{O}^{-14} \mathrm{Kg} \mathrm{m}^{-2} \mathrm{~s}^{-1}\right)$

\begin{tabular}{lllllll}
\hline 0.00 & 0.33 & 0.67 & 1.00 & 1.33 & 1.67 & 2.00
\end{tabular}

Fig. 2. As Fig. 1 but for dibromomethane $\left(10^{-14} \mathrm{~kg} \mathrm{~m}^{-2} \mathrm{~s}^{-1}\right)$. Note the change in scale.

the total global source strength between inventories is more consistent (Table 1), with the exception of Warwick-2011 in which it is $\sim 1.7 \times$ larger than the others. Both Warwick2011 and Ziska-2013 exhibit a significantly stronger $\mathrm{CH}_{2} \mathrm{Br}_{2}$ emission in the tropics relative to Liang-2010 and Ordóñez2012. The Ziska-2013 inventory also contains particularly strong emissions in the Southern Hemisphere (see Ziska et al., 2013).

For minor VSLS $\left(\mathrm{CHBr}_{2} \mathrm{Cl}, \mathrm{CHBrCl}_{2} \& \mathrm{CH}_{2} \mathrm{BrCl}\right)$, emissions are not specified, rather their surface abundance is constrained using an assumed uniform volume mixing ratio $(0.3$, $0.3,0.5 \mathrm{ppt}$ ) based on compiled observations in the tropical MBL (Montzka and Reimann, 2011). Note, Warwick et al. (2006) and Ordóñez et al. (2012) reported emissions for these species but they are not available at present from the other inventories considered. While these minor VSLS are not the focus of this work, they are included in the calculation of $\mathrm{Br}_{\mathrm{y}}^{\mathrm{VSLS}}$ in Sect. 6. As their nominal lifetime is relatively long-lived at the surface (59, 78 and 137 days) (Montzka and Reimann, 2011), the spatial distribution of emission is less important for their troposphere-stratosphere transport (relative to $\mathrm{CHBr}_{3}$ ). 

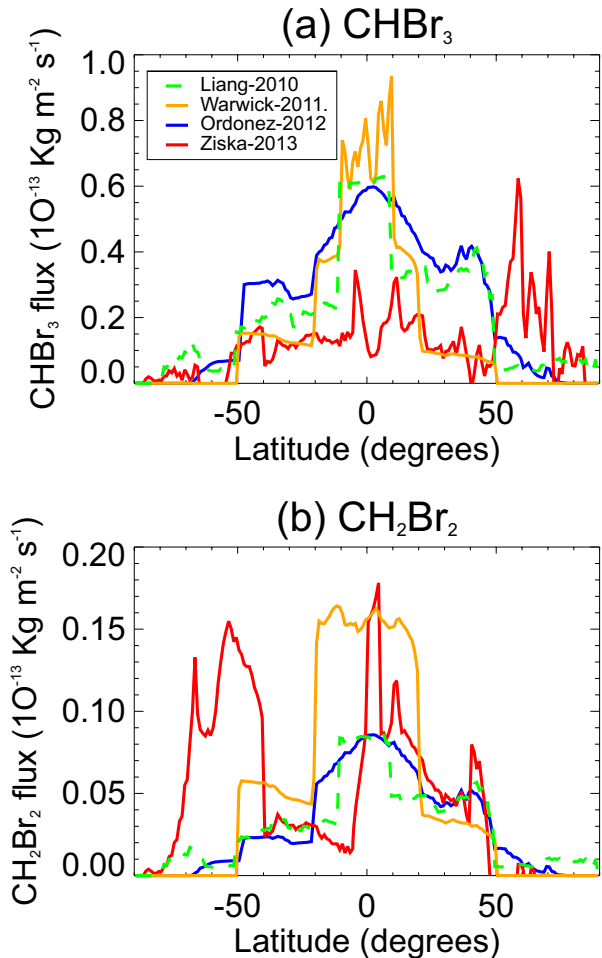

Fig. 3. Zonally averaged global emission source strength $\left(10^{-13} \mathrm{~kg} \mathrm{~m}^{-2} \mathrm{~s}^{-1}\right)$ for (a) $\mathrm{CHBr}_{3}$ and (b) $\mathrm{CH}_{2} \mathrm{Br}_{2}$.

\section{Evaluation of emission inventories with long-term ground-based observations}

Previous model studies have used aircraft observations to validate simulated VSLS profiles in the upper troposphere (e.g. Liang et al., 2010; Ashfold et al., 2012; Hossaini et al., 2012b; Ordóñez et al., 2012). Ideally, global models should be evaluated against observations from multiple platforms. For VSLS, whose emissions are poorly constrained and represent a significant uncertainty in global-scale models, a robust validation of available emission inventories with ground-based observations is desirable. As the tropospherestratosphere transport of VSLS is highly dependant on the location of emissions (Aschmann et al., 2009), validation of both the spatial distribution and magnitude of emissions is needed. However, to date an evaluation of published emission inventories has yet to be be performed.

In this study, multi-annual observations of $\mathrm{CHBr}_{3}$ and $\mathrm{CH}_{2} \mathrm{Br}_{2}$ at 14 ground-based stations (Table 2) have been used to validate modelled fields and test emission estimates. The observed data are from an ongoing cooperative flask sampling program of the National Oceanic and Atmospheric Administration/Earth System Research Laboratory (NOAA/ESRL). Figure 4 shows the location of observations. Whole air samples (WAS) were collected approximately weekly into paired steel or glass flasks and were analysed using gas chromatography/mass spectrometry (GC-MS)
Table 2. Summary and location of NOAA/ESRL ground-based stations arranged from north to south. * Stations SUM, MLO and SPO elevated at $\sim 3210,3397$ and $2810 \mathrm{~m}$ respectively.

\begin{tabular}{llll}
\hline Station & Name & Lat & Lon \\
\hline ALT & Alert, NW Territories, Canada & $82.5^{\circ} \mathrm{N}$ & $62.3^{\circ} \mathrm{W}$ \\
SUM $^{*}$ & Summit, Greenland & $72.6^{\circ} \mathrm{N}$ & $38.4^{\circ} \mathrm{W}$ \\
BRW & Pt. Barrow, Alaska, USA & $71.3^{\circ} \mathrm{N}$ & $156.6^{\circ} \mathrm{W}$ \\
MHD & Mace Head, Ireland & $53.0^{\circ} \mathrm{N}$ & $10.0^{\circ} \mathrm{W}$ \\
LEF & Wisconsin, USA & $45.6^{\circ} \mathrm{N}$ & $90.2^{\circ} \mathrm{W}$ \\
HFM & Massachusetts, USA & $42.5^{\circ} \mathrm{N}$ & $72.2^{\circ} \mathrm{W}$ \\
THD & Trinidad Head, USA & $41.0^{\circ} \mathrm{N}$ & $124.0^{\circ} \mathrm{W}$ \\
NWR & Niwot Ridge, Colorado, USA & $40.1^{\circ} \mathrm{N}$ & $105.6^{\circ} \mathrm{W}$ \\
KUM & Cape Kumukahi, Hawaii, USA & $19.5^{\circ} \mathrm{N}$ & $154.8^{\circ} \mathrm{W}$ \\
MLO* & Mauna Loa, Hawaii, USA & $19.5^{\circ} \mathrm{N}$ & $155.6^{\circ} \mathrm{W}$ \\
SMO & Cape Matatula, American Samoa & $14.3^{\circ} \mathrm{S}$ & $170.6^{\circ} \mathrm{W}$ \\
CGO & Cape Grim, Tasmania, Australia & $40.7^{\circ} \mathrm{S}$ & $144.8^{\circ} \mathrm{E}$ \\
PSA & Palmer Station, Antarctica & $64.6^{\circ} \mathrm{S}$ & $64.0^{\circ} \mathrm{W}$ \\
SPO* & South Pole & $90.0^{\circ} \mathrm{S}$ & - \\
\hline
\end{tabular}

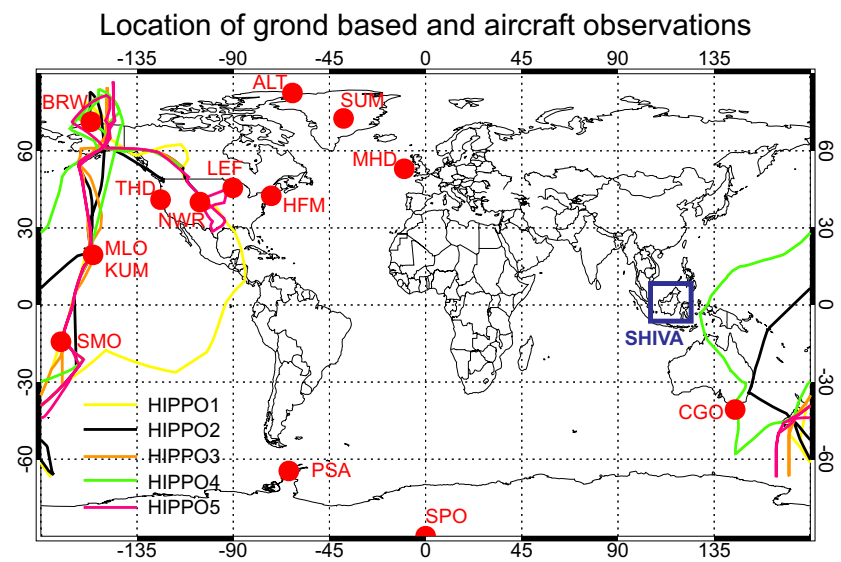

Fig. 4. Location of NOAA/ESRL ground-based monitoring stations. Note, the close proximity of stations MLO and KUM (see Table 2). In this work we group the stations into 5 latitude bands; high $\mathrm{NH}$ $\left(\geq 60^{\circ} \mathrm{N}\right)$, midlatitude $\mathrm{NH}\left(30-60^{\circ} \mathrm{N}\right)$, tropical $\left( \pm 30^{\circ}\right)$, midlatitude $\mathrm{SH}\left(30-60^{\circ} \mathrm{S}\right)$ and high $\mathrm{SH}\left(\geq 60^{\circ} \mathrm{S}\right)$. Also shown are the flight tracks from the NSF HIPPO aircraft campaigns (1-5) which took place between 2009 and 2011 (see Sect. 4). The location of the SHIVA aircraft campaign (see Sect. 5) that took place in the tropical western Pacific during Nov-Dec 2011 is also indicated.

(Montzka et al., 2003). NOAA data from flasks collected at surface sites and also on the HIPPO aircraft campaign are presented relative to the NOAA-2003 scale for $\mathrm{CH}_{2} \mathrm{Br}_{2}$ and the NOAA-2004 scale for $\mathrm{CHBr}_{3}$. These scales consist of 2-4 standards prepared with gravimetric techniques at 3$20 \mathrm{ppt}$ in high-pressure (900 psi initially) $30 \mathrm{~L}$, electropolished stainless steel cannisters.

Figure 5 shows the NOAA/ESRL observed $\mathrm{CHBr}_{3}$ mixing ratio at these stations (north-south). The observed data points are monthly mean fields that have been calculated from a $14 \mathrm{yr}$ monthly mean data set (i.e. we have taken the mean of 


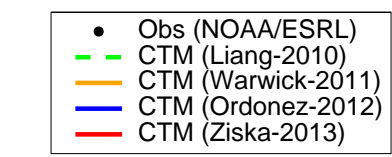

BRW

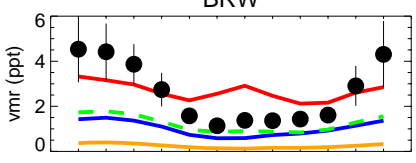

HFM

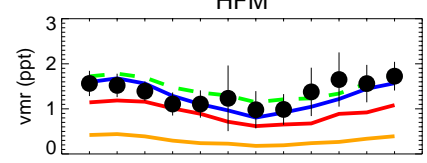

KUM

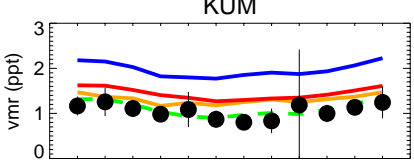

CGO

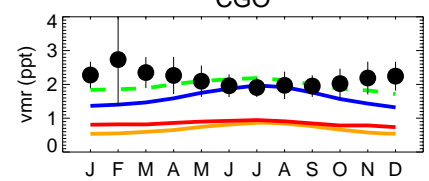

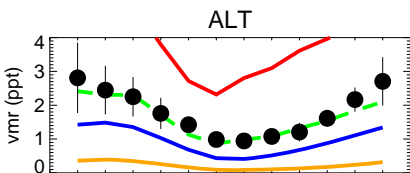

MHD

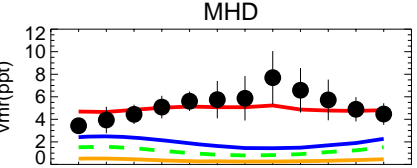

THD

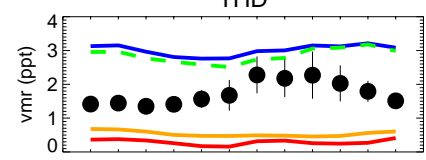

MLO

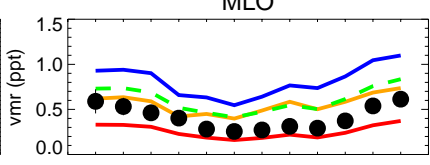

PSA

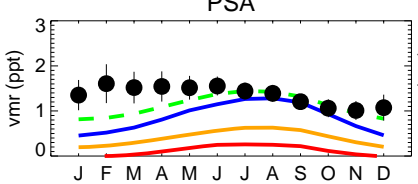

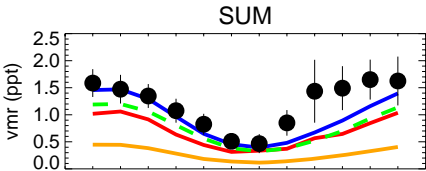

LEF

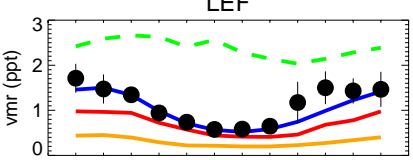

NWR

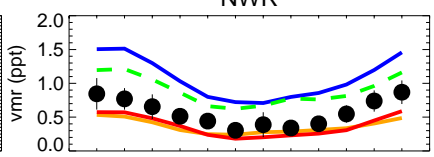

SMO

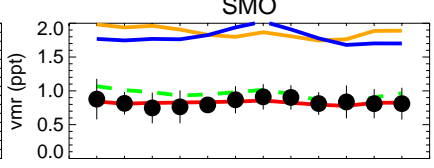

SPO

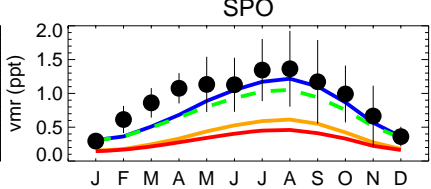

Fig. 5. Comparison of observed monthly mean $\mathrm{CHBr}_{3}$ mixing ratio (ppt) at 14 NOAA/ESRL ground stations with output from TOMCAT runs $S_{\text {Liang }}$ (Liang-2010 emissions), $S_{\text {Warwick }}$ (Warwick-2011 emissions), $S_{\text {Ordonez }}$ (Ordóñez-2012 emissions) and $S_{\text {Ziska }}($ Ziska-2013 emissions). The vertical bars denote \pm 1 standard deviation on the observed mean (see text for details).

monthly mean fields). This approach smooths intra-monthly variability but can give a clear signal of seasonal variations. The observations spanned the period 1 January 98 to 1 January 2012 at all stations except SPO, THD, and SUM, which are shorter records. Also shown in Fig. 5 is the corresponding modelled $\mathrm{CHBr}_{3}$ mixing ratio from runs $S_{\text {Liang }}, S_{\text {Warwick, }}$, $S_{\text {Ordonez }}$ and $S_{\text {Ziska }}$. The CTM was run for the same (14 yr) period following $3 \mathrm{yr}$ of spin-up. Monthly mean data was output allowing a like-for-like comparison between model and observation.

At $\mathrm{NH}$ high-latitude $\left(\geq 60^{\circ}\right)$ stations (ALT, SUM and BRW), observed $\mathrm{CHBr}_{3}$ exhibits a pronounced seasonal cycle with elevated mixing ratios during $\mathrm{NH}$ winter (DJF). This seasonality, likely due to the enhanced photochemical sink of $\mathrm{CHBr}_{3}$ during summer (JJA) months (or potentially transport), has been previously observed (at ALT) by Yokouchi et al. (1996). The CTM captures this seasonality, particularly at ALT and SUM, where the bias between model and observation is highly dependent on the emission inventory used. The top-down inventories (Liang-2010, Warwick2011 and Ordóñez-2012) on average underestimate observed $\mathrm{CHBr}_{3}$ at these high-latitude NH stations (Fig. 5). The calculated mean bias (model minus observation) for the entire $14 \mathrm{yr}$ monthlymean data set is $-0.65,-1.61$ and $-0.88 \mathrm{ppt}$ for these inventories, respectively. The bottom-up estimate of Ziska-2013 overestimates with a positive mean bias of $+0.54 \mathrm{ppt}$. This is skewed by the significant overestimation of $\mathrm{CHBr}_{3}$ at ALT. It was previously shown in Fig. 3 that Ziska-2013 exhibits a significantly larger $\mathrm{CHBr}_{3}$ source at high $\mathrm{NH}$ latitudes over the other inventories considered.

At NH midlatitude (30-60 $\mathrm{N}$ ) stations (MHD, LEF, HFM, THD and NWR), the agreement between model and observation varies significantly with emission inventory. At Mace Head (MHD), the top-down inventories underestimate the large background $\mathrm{CHBr}_{3}$ (up to $\sim 8 \mathrm{ppt}$ ). However, the larger bottom-up emissions of Ziska-2013 in this region lead to a reasonable agreement between model and observation. Note, here the seasonal cycle is out of expected phase, as a $\mathrm{CHBr}_{3}$ minimum is observed during winter months and a maximum during summer. Carpenter et al. (2005) observed a similar seasonality and deduced that strong local emissions (during summer) dominate over enhanced photochemical loss to control the local $\mathrm{CHBr}_{3}$ abundance at MHD.

For VSLS, transport to the stratosphere is most efficient in tropical regions where convection can rapidly loft boundary layer air into the mid/upper troposphere (e.g. Aschmann et al., 2009). At tropical $\left( \pm 30^{\circ}\right)$ stations KUM and MLO there is also noticeable seasonality in observed $\mathrm{CHBr}_{3}$. This is in phase with most other NH stations and indicative of larger-scale processes (likely the photochemical sink) controlling the seasonality. The bias between the model and observation is again varied and strongly dependent on emission 


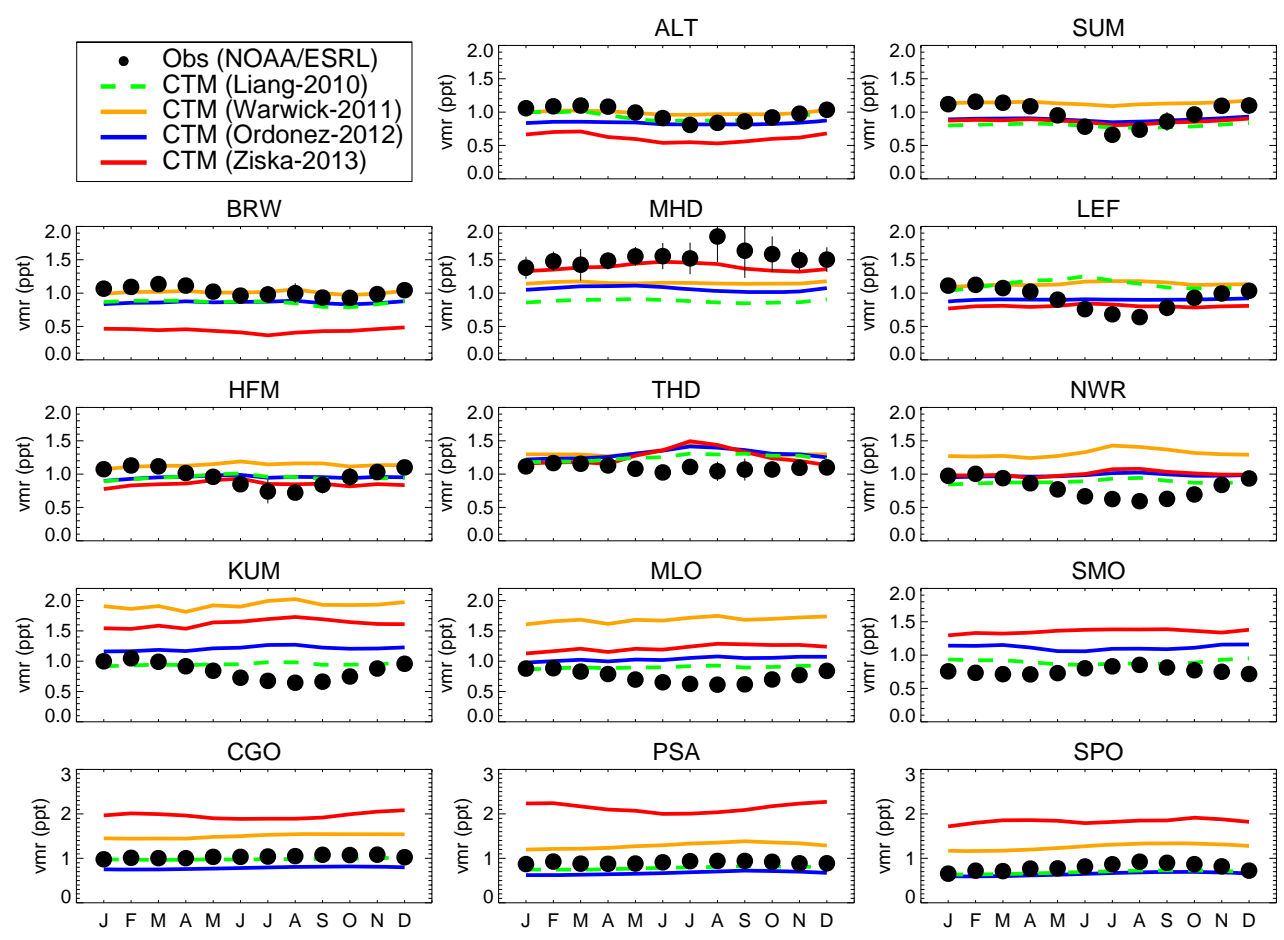

Fig. 6. As Fig. 5 but for $\mathrm{CH}_{2} \mathrm{Br}_{2}$.

inventory. The Ordóñez-2012 emissions, which are weighted towards a seasonal climatology of chlorophyll $a$ in the tropics, lead to an overestimate of $\mathrm{CHBr}_{3}$ at each tropical station (KUM, MLO and SMO), and for all months. For these stations the mean bias is $0.12,0.48,0.76$ and $0.07 \mathrm{ppt}$ for runs $S_{\text {Liang }}, S_{\text {Warwick }}, S_{\text {Ordonez }}$ and $S_{\text {Ziska }}$, respectively. This indicates that the Liang-2010 (top-down) and the Ziska-2013 (bottom-up) derived $\mathrm{CHBr}_{3}$ emissions perform particularly well at these locations in the tropical Pacific.

In the $\mathrm{SH}$, long-term observations of VSLS are particularly sparse. In the $\mathrm{SH}$ midlatitude $\left(30-60^{\circ} \mathrm{S}\right)$ band, data from just one station is available (CGO). Here, $\mathrm{CHBr}_{3}$ is generally underestimated but reasonable agreement is obtained with the Liang-2010 and Ordóñez-2012 inventories. This is also the case at the two high-latitude $\mathrm{SH}$ stations $\left(60-90^{\circ} \mathrm{S}\right)$ PSA and SPO. Here, a clear seasonal cycle is apparent at the latter with a $\mathrm{CHBr}_{3}$ maximum occurring during $\mathrm{SH}$ winter (JJA), consistent with Swanson et al. (2004) and Beyersdorf et al. (2010) who note a similar seasonality. The CTM is able to reproduce this seasonality well, which is likely driven by photochemistry, and again the Liang-2010 and Ordóñez2012 scenarios provide the best agreement.

For $\mathrm{CH}_{2} \mathrm{Br}_{2}$, a similar comparison between the observations and the model has been performed (Fig. 6). Photolysis is a minor tropospheric sink for $\mathrm{CH}_{2} \mathrm{Br}_{2}$, which has a nominal surface lifetime of $\sim 120$ days (Montzka and Reimann, 2011), and whose dominant sink is by reaction with $\mathrm{OH}$. As its lifetime is significantly longer than that of $\mathrm{CHBr}_{3}$
( $\sim 26$ days), horizontal gradients are expected to be less pronounced. The observations show background mixing ratios in the range of $\sim 0.5-1.5 \mathrm{ppt}$ at all stations (excluding MHD) with generally low variability. Seasonality is apparent at most sites in the NH (e.g. ALT, SUM, LEF, NWR, KUM, MLO etc.), and is likely due to seasonal changes to the $\mathrm{CH}_{2} \mathrm{Br}_{2}+$ $\mathrm{OH}$ loss rate. The magnitude of relative variation is smaller than that for $\mathrm{CHBr}_{3}$ due to the significantly longer lifetime of $\mathrm{CH}_{2} \mathrm{Br}_{2}$.

The global $\mathrm{CH}_{2} \mathrm{Br}_{2}$ source strength is relatively similar for 3 out of the 4 inventories considered: $62-67 \mathrm{Gg} \mathrm{yr}^{-1}$, among Liang-2010, Ordóñez-2012 and Ziska-2013. However, it is significantly larger $\left(113 \mathrm{Gg} \mathrm{yr}^{-1}\right)$ in the Warwick-2011 inventory. Also, the latitudinal distribution of emissions, including in the tropics, varies significantly between inventories (e.g. Fig. 3). At tropical stations KUM, MLO and SMO, $\mathrm{CH}_{2} \mathrm{Br}_{2}$ is overestimated when using Warwick-2011 and Ziska-2013 emissions. At these stations, improved agreement is obtained using Ordóñez-2012 and good agreement using Liang-2010. In the $\mathrm{SH}$, between $\sim 40$ and $75^{\circ} \mathrm{S}$, the Ziska-2013 inventory exhibits a particularly strong $\mathrm{CH}_{2} \mathrm{Br}_{2}$ source (see Fig. 3), not featured in the other inventories. Comparison of modelled $\mathrm{CH}_{2} \mathrm{Br}_{2}$ with observations within this latitude range (i.e. CGO and PSA sites) show a significant overestimation of $\mathrm{CH}_{2} \mathrm{Br}_{2}$, by an approximate factor of 2, when using the Ziska-2013 inventory.

For a more quantitative evaluation of the modelled $\mathrm{CHBr}_{3}$ and $\mathrm{CH}_{2} \mathrm{Br}_{2}$ fields with these long-term surface observations, 
Table 3. Summary of calculated error metrics between NOAA/ESRL observed surface $\mathrm{CHBr}_{3}$ with analogous fields from CTM runs $S_{\text {Liang }}$, $S_{\text {Ziska }}, S_{\text {Warwick }}$ and $S_{\text {Ordonez }}$. Shown is the mean bias (MB) and the mean absolute deviation (MAD) both in units of ppt. Also shown is the mean absolute percentage error (MAPE, see text). These fields were calculated for the entire $14 \mathrm{yr}$ period of available observation (1 January 1998-1 January 2012) and for the 5 latitudinal bands shown in Fig. 4. The global values shown are a comparison for all 14 stations.

\begin{tabular}{lrrr|rrr|rr|rr|rr}
\hline \multirow{2}{*}{ Latitude } & \multicolumn{3}{c}{ Run $S_{\text {Liang }}$} & \multicolumn{3}{c|}{ Run $S_{\text {Warwick }}$} & \multicolumn{2}{c|}{ Run $S_{\text {Ordonez }}$} & \multicolumn{2}{c}{ Run $S_{\text {Ziska }}$} \\
\cline { 2 - 12 } & MB & MAD & MAPE & MB & MAD & MAPE & MB & MAD & MAPE & MB & MAD & MAPE \\
\hline$\geq 60^{\circ} \mathrm{N}$ & -0.65 & 0.73 & $33 \%$ & -1.61 & 1.61 & $84 \%$ & -0.88 & 0.91 & $42 \%$ & 0.54 & 1.24 & $79 \%$ \\
$30-60^{\circ} \mathrm{N}$ & -0.25 & 1.45 & $84 \%$ & -1.64 & 1.64 & $67 \%$ & -0.35 & 1.15 & $59 \%$ & -0.57 & 0.77 & $42 \%$ \\
$\pm 30^{\circ}$ & 0.12 & 0.22 & $38 \%$ & 0.48 & 0.52 & $77 \%$ & 0.76 & 0.78 & $115 \%$ & 0.07 & 0.26 & $36 \%$ \\
$30-60^{\circ} \mathrm{S}$ & -0.20 & 0.45 & $19 \%$ & -1.48 & 1.48 & $67 \%$ & -0.54 & 0.63 & $26 \%$ & -1.32 & 1.32 & $59 \%$ \\
$\geq 60^{\circ} \mathrm{S}$ & -0.24 & 0.32 & $28 \%$ & -0.75 & 0.75 & $61 \%$ & -0.32 & 0.40 & $33 \%$ & -0.93 & 0.93 & $77 \%$ \\
Global & -0.25 & 0.80 & $50 \%$ & -1.04 & 1.25 & $72 \%$ & -0.24 & 0.87 & $61 \%$ & -0.30 & 0.82 & $55 \%$ \\
\hline
\end{tabular}

Table 4. As Table 3 but for $\mathrm{CH}_{2} \mathrm{Br}_{2}$.

\begin{tabular}{|c|c|c|c|c|c|c|c|c|c|c|c|c|}
\hline \multirow[t]{2}{*}{ Latitude } & \multicolumn{3}{|c|}{ Run $S_{\text {Liang }}$} & \multicolumn{3}{|c|}{ Run $S_{\text {Warwick }}$} & \multicolumn{3}{|c|}{ Run $S_{\text {Ordonez }}$} & \multicolumn{3}{|c|}{ Run $S_{\text {Ziska }}$} \\
\hline & MB & MAD & MAPE & MB & MAD & MAPE & MB & MAD & MAPE & MB & MAD & MAPE \\
\hline$\geq 60^{\circ} \mathrm{N}$ & -0.11 & 0.15 & $15 \%$ & 0.08 & 0.14 & $16 \%$ & -0.11 & 0.15 & $15 \%$ & -0.34 & 0.36 & $36 \%$ \\
\hline $30-60^{\circ} \mathrm{N}$ & -0.03 & 0.28 & $27 \%$ & 0.18 & 0.33 & $37 \%$ & -0.00 & 0.24 & $24 \%$ & 0.02 & 0.21 & $22 \%$ \\
\hline $\pm 30^{\circ}$ & 0.14 & 0.17 & $24 \%$ & 1.25 & 1.25 & $167 \%$ & 0.35 & 0.35 & $49 \%$ & 0.63 & 0.63 & $85 \%$ \\
\hline $30-60^{\circ} \mathrm{S}$ & -0.05 & 0.10 & $10 \%$ & 0.47 & 0.49 & $48 \%$ & -0.25 & 0.25 & $23 \%$ & 0.93 & 0.94 & $92 \%$ \\
\hline$\geq 60^{\circ} \mathrm{S}$ & -0.11 & 0.12 & $13 \%$ & 0.43 & 0.45 & $55 \%$ & -0.19 & 0.19 & $21 \%$ & 1.14 & 1.14 & $137 \%$ \\
\hline Global & -0.02 & 0.19 & $20 \%$ & 0.44 & 0.52 & $64 \%$ & 0.00 & 0.24 & $27 \%$ & 0.30 & 0.52 & $60 \%$ \\
\hline
\end{tabular}

three error metrics were calculated (Tables 3,4); the mean bias (MB) (ppt), calculated using Eq.(1), the mean absolute deviation (MAD) (ppt), calculated using Eq.(2), and the mean absolute percentage error (MAPE), using Eq.(3), for the 5 latitudinal bands considered. Here, $M$ and $O$ denote the monthly modelled and observed fields for the entire $14 \mathrm{yr}$ period of comparison, respectively. The total number of comparison points $(n)$ is 168 .

$\mathrm{MB}=\frac{1}{n} \sum_{t=1}^{n}\left(M_{t}-O_{t}\right)$

$\mathrm{MAD}=\frac{1}{n} \sum_{t=1}^{n}\left|M_{t}-O_{t}\right|$

MAPE $=\frac{100}{n} \sum_{t=1}^{n}\left|\frac{M_{t}-O_{t}}{O_{t}}\right|$

Based on the reported error metrics it is clear the performance of each inventory varies significantly by region. Focusing on the important tropical latitude band, for $\mathrm{CHBr}_{3}$ the MAPE between model and observation ranges between $36 \%$ and $115 \%$. The best agreement, diagnosed by the lowest MAPE ( $36 \%$ ), is obtained from run $S_{\text {Ziska }}$ (bottom-up emissions). $S_{\text {Liang }}$ also performs well in the tropics with a similar MAPE of $38 \%$, which is significantly lower than runs $S_{\text {Warwick }}$ and $S_{\text {Ordonez }}$. Note, small values of observed $\mathrm{CHBr}_{3}$ can cause large skew in the calculated MAPE (see Eq. 3). For $\mathrm{CH}_{2} \mathrm{Br}_{2}$, MAPE ranges from 24 to $166 \%$ in the tropics. The best agreement is obtained from run $S_{\text {Liang }}(24 \%)$, using the Liang-2010 inventory which has the lowest total emissions in the tropics and also the lowest global total (see Fig. 3 also). The calculated mean bias presented in Table 4 confirms the significant overestimation of $\mathrm{CH}_{2} \mathrm{Br}_{2}$ by runs $S_{\text {Warwick }}$ and $S_{\text {Ziska }}$ suggesting a significant overestimate of the tropical $\mathrm{CH}_{2} \mathrm{Br}_{2}$ source in these emissions inventories.

Overall, the global performance (all stations) of each scenario can be assessed based on the error metrics in Table 3 . Globally, the best agreement between model and observation, for both $\mathrm{CHBr}_{3}$ and $\mathrm{CH}_{2} \mathrm{Br}_{2}$, is obtained for run $S_{\text {Liang }}$; the global MAPE using the Liang-2010 inventory is 50 and $20 \%$ for these species, respectively. To support this conclusion, further long-term observations of VSLS would be desirable, particularly in the tropics and in the poorly sampled Southern Hemisphere. While the NOAA/ESRL observations are a valuable long-term record, the spatial distribution of sampling is limited in these regions. Therefore, we also consider recent aircraft observations of $\mathrm{CHBr}_{3}$ and $\mathrm{CH}_{2} \mathrm{Br}_{2}$ made during the HIPPO aircraft campaigns over the Pacific Basin that spanned global latitudes (Sect. 4). Observations of VSLS made in the poorly sampled tropical western Pacific during 
the SHIVA campaign are also considered in a case study (Sect. 5).

The error metrics presented in Tables 3 and 4 were computed for all months. To examine any potential systematic seasonal bias between the model and the observations, probability density functions (PDF) have been computed by season and latitude band (see supplementary material). For both $\mathrm{CHBr}_{3}$ and $\mathrm{CH}_{2} \mathrm{Br}_{2}$, no clear systematic seasonal bias is apparent. The skill of the model in reproducing the observations is highly dependent on the magnitude/distribution of emissions, which were previously shown to vary significantly. The seasonality of these gases, observed at numerous ground-based stations, is generally well captured by aseasonal emissions ( 3 of the 4 inventories). This suggests at these sites the seasonality is largely driven by photochemistry; i.e. sinks that are well represented in the model.

\section{Evaluation of emission inventories with HIPPO aircraft data}

The HIAPER Pole-to-Pole Observations (HIPPO) project consisted of a series of aircraft campaigns between 2009 and 2011 supported by the National Science Foundation (NSF). Five missions were conducted (January 2009, November 2009, March/April 2010, June 2011 and August/September 2011). The aim of HIPPO was to make global measurements of various trace gases, including greenhouse gases $\mathrm{CO}_{2}, \mathrm{CH}_{4}, \mathrm{~N}_{2} \mathrm{O}$ and also $\mathrm{CO}, \mathrm{SF}_{6}, \mathrm{CFCs}$ and brominecontaining VSLS (Wofsy et al., 2011). Sampling spanned a range of latitudes, from near the North Pole to coastal Antarctica, on board the NSF Gulfstream V aircraft and from the surface to $\sim 14 \mathrm{~km}$ over the Pacific Basin. As such, these comprehensive data complement the long-term observations of VSLS discussed in Sect. 3 and allow for further evaluation of the model with varying emission inventories of $\mathrm{CHBr}_{3}$ and $\mathrm{CH}_{2} \mathrm{Br}_{2}$. The HIPPO data is particularly valuable for this analysis as it is independent, i.e. has not been used in constructing the emission inventories considered. The data is archived at the following web address: http://www.eol.ucar.edu/projects/hippo/.

Figures 7 and 8 compare mean observed profiles of $\mathrm{CHBr}_{3}$ and $\mathrm{CH}_{2} \mathrm{Br}_{2}$, made during HIPPO 1-5, with modelled TOMCAT profiles for the 5 latitude bands considered in this work. The observations here were collected using whole air samples, in stainless steel and glass flasks, and analysed by two different laboratories by gas chromatography/mass spectrometry (GC-MS); NOAA/ESRL and the University of Miami. Mixing ratios from HIPPO are reported on the same calibration scale as the NOAA/ESRL ground-based station results. The model has here been sampled for each flight track to match the observations and allowing a point-by-point comparison throughout the profiles. To assess the skill of the model against the HIPPO observations, three error metrics were again computed; the MB (ppt), calculated using Eq.(1), the MAD (ppt), calculated using Eq.(2), and the MAPE, using Eq.(3), for the 5 latitudinal bands considered. These are summarised in Tables 5 and 6 for $\mathrm{CHBr}_{3}$ and $\mathrm{CH}_{2} \mathrm{Br}_{2}$, respectively.

In general, the model is able to reproduce the observed vertical distribution of $\mathrm{CHBr}_{3}$ well in all latitude bands. The overall skill of the model is highly dependent on the given emission inventory. At high latitudes in the $\mathrm{NH}\left(\geq 60^{\circ} \mathrm{N}\right)$, the MAPE between the model and observation ranges from $\sim 31$ to $63 \%$ across HIPPO 1-5. As was reported in Sect. 3 using ground-based data, the best agreement, diagnosed by the lowest MAPE, is obtained from $S_{\text {Liang. We find run }}$ $S_{\text {Liang }}$ also gives the best agreement with observed $\mathrm{CHBr}_{3}$ within the $30-60^{\circ} \mathrm{N}$ latitude band, where MAPE ranges between 28 and $51 \%$. In the tropics $\left( \pm 30^{\circ}\right)$, it was previously shown in Sect. 3 that run $S_{\text {Ziska }}$, with bottom-up derived emissions from sea-to-air fluxes, performed particularly well against long-term NOAA/ESRL ground-based observations. Based on the comparison with HIPPO observations here, run

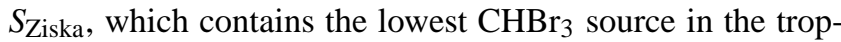
ics (e.g. Fig. 3), is again found to give the best agreement in the tropics. Here, the MAPE ranges from $\sim 35$ to $102 \%$ with runs $S_{\text {Ziska }}$ and $S_{\text {Ordonez }}$ accounting for this lower and upper limit, respectively. The significant overestimate of $\mathrm{CHBr}_{3}$ from $S_{\text {Ordonez, }}$ along with the similar reported overestimate found from the ground-based analysis, suggests that $\mathrm{CHBr}_{3}$ emissions from the Ordóñez-2012 inventory may be too large within the $\pm 30^{\circ}$ latitude band.

In the $\mathrm{SH}$, where the coverage provided from the groundbased stations is limited, HIPPO made a number of observations. Within the $30-60^{\circ} \mathrm{S}$ band, the model performs reasonably well with the MAPE ranging from $\sim 39$ to $69 \%$. The lower and upper limit is given by runs $S_{\text {Warwick }}$ and $S_{\text {Ordonez }}$, respectively. At high latitudes in the $\mathrm{SH}\left(60-90^{\circ} \mathrm{S}\right)$, observations are limited relative to other latitude bands, however some profiles are available for analysis. Note, the exception being for HIPPO-4, during which observations $\geq 60^{\circ} \mathrm{S}$ were particularly sparse. Nevertheless, in this region the model performs reasonably well with MAPE ranging from $\sim 42$ to $62 \%$ with the best agreement from run $S_{\text {Liang. }}$.

To determine which $\mathrm{CHBr}_{3}$ emission inventory gives best agreement globally, i.e. spanning the range of latitudes covered by HIPPO, we have also calculated a global MAPE (Table 5). Globally, the best agreement (lowest MAPE) between the model and observation is obtained from runs $S_{\text {Liang }}$ and $S_{\text {Ziska }}$, where MAPE is $\sim 40 \%$ for both. This supports the findings in Sect. 3, where it was also shown that the Liang2010 and Ziska-2013 emission inventories give the best agreement with long-term NOAA/ESRL ground-based observations of $\mathrm{CHBr}_{3}$. Note, while the global MAPE happens to be similar for these two runs, differences within the 5 latitudes bands are apparent. For example, in the tropics $\left( \pm 30^{\circ}\right)$, as noted, the better agreement is obtained from the lower (Ziska-2013) bottom-up emissions (MAPE 35\%). In fact, this is the only inventory that results in a MAPE $<50 \%$ for 
Table 5. Summary of calculated error metrics between $\mathrm{CHBr}_{3}$ observed in the free troposphere during the HIPPO project (2009-2011) with analogous fields from CTM runs $S_{\text {Liang }}, S_{\text {Warwick }}, S_{\text {Ordonez }}$ and $S_{\text {Ziska }}$. Shown are the MB and the MAD both in units of ppt. Also shown is the MAPE (see text). These fields were calculated for all observations made during HIPPO missions 1-5 for the 5 latitudinal bands shown in Fig. 4. A global value is also quoted for comparisons at all latitudes.

\begin{tabular}{lrrr|rrr|rrr|rr|r|r|}
\hline \multirow{2}{*}{ Latitude } & \multicolumn{3}{c}{ Run $S_{\text {Liang }}$} & \multicolumn{3}{c|}{ Run $S_{\text {Warwick }}$} & \multicolumn{3}{c|}{ Run $S_{\text {Ordonez }}$} & \multicolumn{2}{c}{ Run $S_{\text {Ziska }}$} \\
\cline { 2 - 12 } & MB & MAD & MAPE & MB & MAD & MAPE & MB & MAD & MAPE & MB & MAD & MAPE \\
\hline$\geq 60^{\circ} \mathrm{N}$ & -0.16 & 0.23 & $31 \%$ & -0.55 & 0.55 & $63 \%$ & -0.03 & 0.24 & $37 \%$ & -0.25 & 0.26 & $38 \%$ \\
$30-60^{\circ} \mathrm{N}$ & 0.04 & 0.12 & $28 \%$ & -0.27 & 0.29 & $42 \%$ & 0.22 & 0.23 & $51 \%$ & -0.25 & 0.25 & $42 \%$ \\
$\pm 30^{\circ}$ & 0.30 & 0.31 & $63 \%$ & 0.32 & 0.33 & $68 \%$ & 0.51 & 0.51 & $102 \%$ & -0.19 & 0.20 & $35 \%$ \\
$30-60^{\circ} \mathrm{S}$ & 0.09 & 0.13 & $45 \%$ & -0.07 & 0.13 & $39 \%$ & 0.19 & 0.21 & $69 \%$ & -0.18 & 0.19 & $42 \%$ \\
$\geq 60^{\circ} \mathrm{S}$ & -0.12 & 0.21 & $42 \%$ & -0.37 & 0.40 & $60 \%$ & 0.06 & 0.28 & $62 \%$ & -0.40 & 0.41 & $54 \%$ \\
Global & 0.04 & 0.20 & $42 \%$ & -0.17 & 0.34 & $54 \%$ & 0.21 & 0.30 & $65 \%$ & -0.24 & 0.25 & $41 \%$ \\
\hline
\end{tabular}

\section{HIPPO-1}
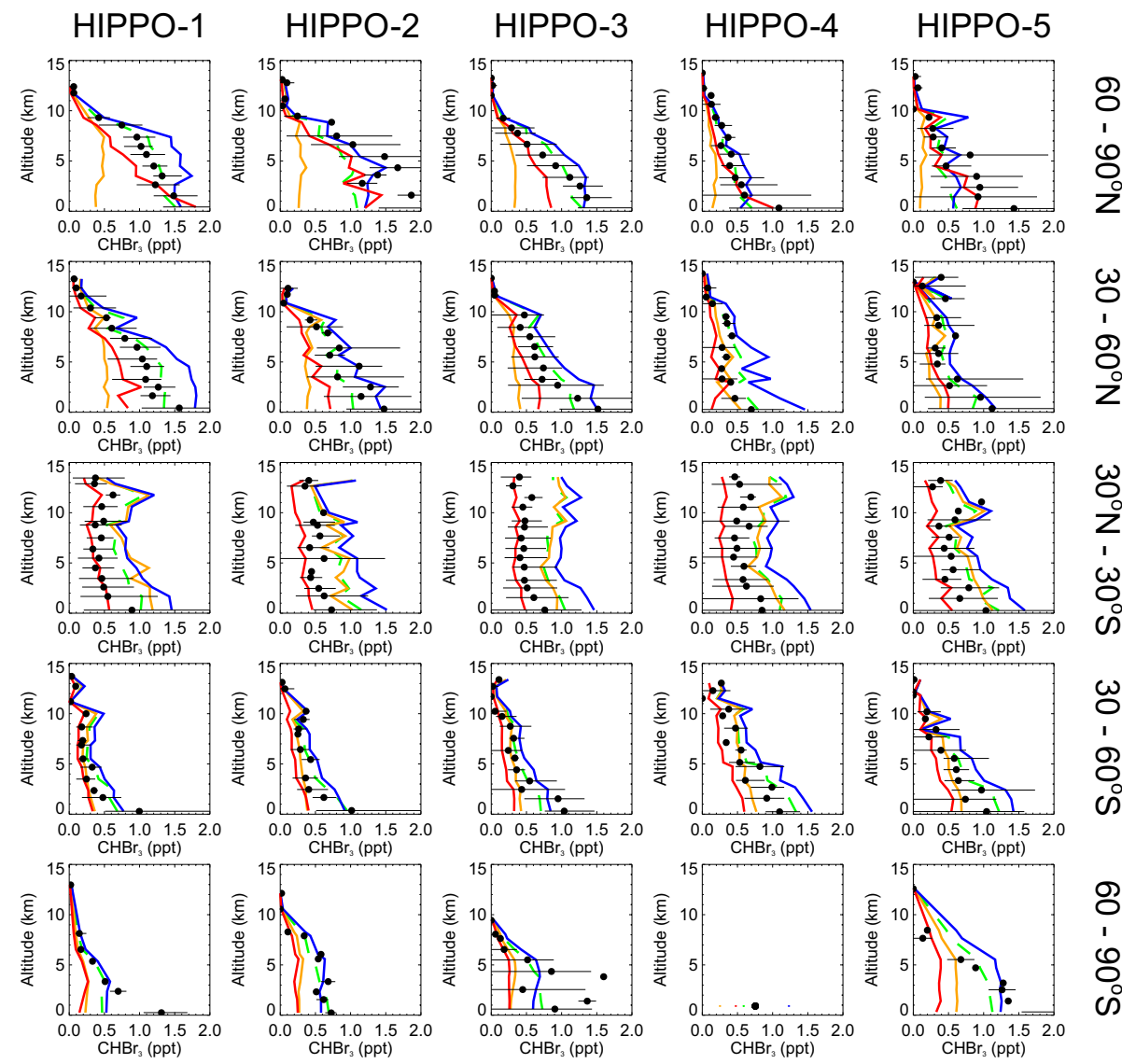

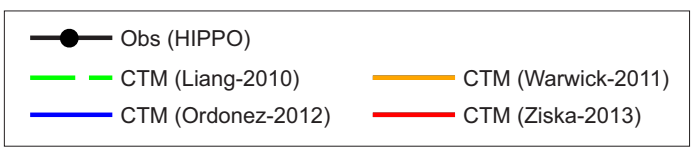

Fig. 7. Comparison of observed $\mathrm{CHBr}_{3}$ profiles (ppt) made during the NSF HIPPO project (campaigns 1-5, 2009-2011) with analogous modelled profiles from TOMCAT runs $S_{\text {Liang }}, S_{\text {Warwick }}, S_{\text {Ordonez }}$ and $S_{\text {Ziska }}$. All profiles shown are the average for the 5 latitudinal bands considered in this work and are also averaged vertically in $\sim 1 \mathrm{~km}$ bins. The horizontal lines on the observed data denote the min-max variability from the mean. Note, very few observations were made during HIPPO-4 between 60 and $90^{\circ} \mathrm{S}$. 
Table 6. As Table 5 but for $\mathrm{CH}_{2} \mathrm{Br}_{2}$.

\begin{tabular}{lrrr|rrr|rr|rr|rr}
\hline \multirow{2}{*}{ Latitude } & \multicolumn{3}{c|}{ Run $S_{\text {Liang }}$} & \multicolumn{3}{c|}{ Run $S_{\text {Warwick }}$} & \multicolumn{2}{c|}{ Run $S_{\text {Ordonez }}$} & \multicolumn{3}{c}{ Run $S_{\text {Ziska }}$} \\
\cline { 2 - 12 } & MB & MAD & MAPE & MB & MAD & MAPE & MB & MAD & MAPE & MB & MAD & MAPE \\
\hline$\geq 60^{\circ} \mathrm{N}$ & -0.10 & 0.17 & $23 \%$ & 0.25 & 0.29 & $57 \%$ & -0.02 & 0.16 & $24 \%$ & -0.12 & 0.28 & $39 \%$ \\
$30-60^{\circ} \mathrm{N}$ & -0.02 & 0.15 & $19 \%$ & 0.47 & 0.47 & $75 \%$ & 0.08 & 0.17 & $25 \%$ & 0.11 & 0.25 & $37 \%$ \\
$\pm 30^{\circ}$ & 0.12 & 0.13 & $16 \%$ & 1.11 & 1.11 & $134 \%$ & 0.24 & 0.24 & $29 \%$ & 0.54 & 0.54 & $66 \%$ \\
$30-60^{\circ} \mathrm{S}$ & -0.01 & 0.09 & $13 \%$ & 0.67 & 0.67 & $101 \%$ & 0.01 & 0.12 & $18 \%$ & 0.55 & 0.55 & $77 \%$ \\
$\geq 60^{\circ} \mathrm{S}$ & -0.09 & 0.13 & $18 \%$ & 0.43 & 0.43 & $69 \%$ & -0.06 & 0.17 & $23 \%$ & 0.55 & 0.73 & $96 \%$ \\
Global & -0.01 & 0.13 & $18 \%$ & 0.60 & 0.61 & $88 \%$ & 0.06 & 0.17 & $24 \%$ & 0.30 & 0.45 & $60 \%$ \\
\hline
\end{tabular}

HIPPO-1
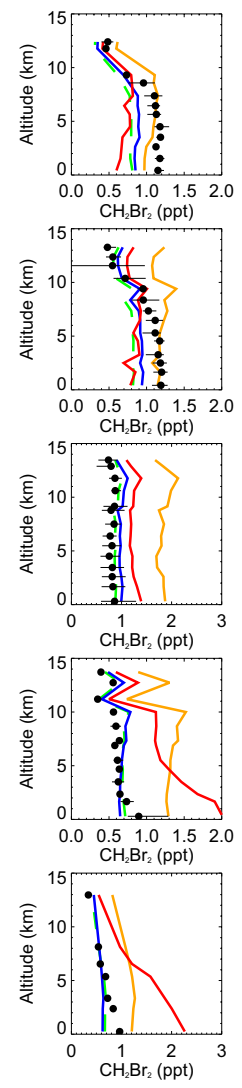

HIPPO-3
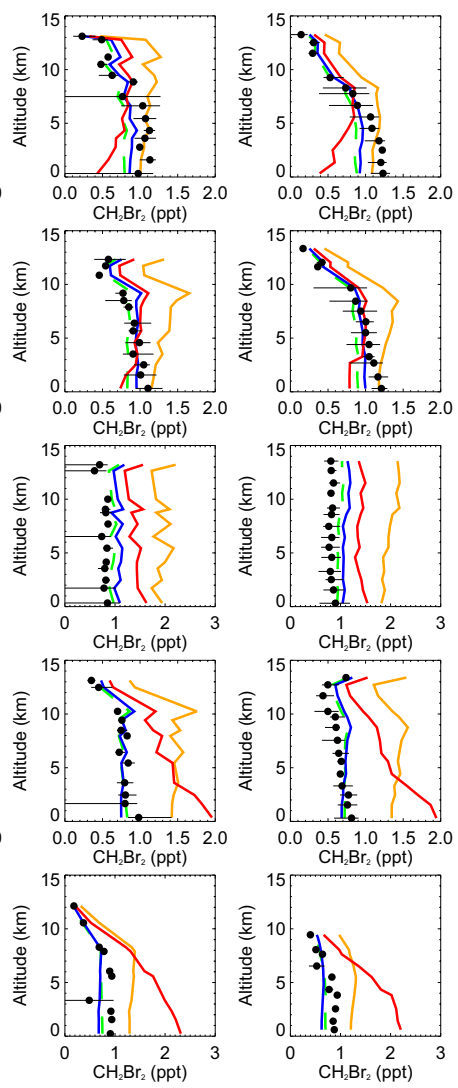

HIPPO-4
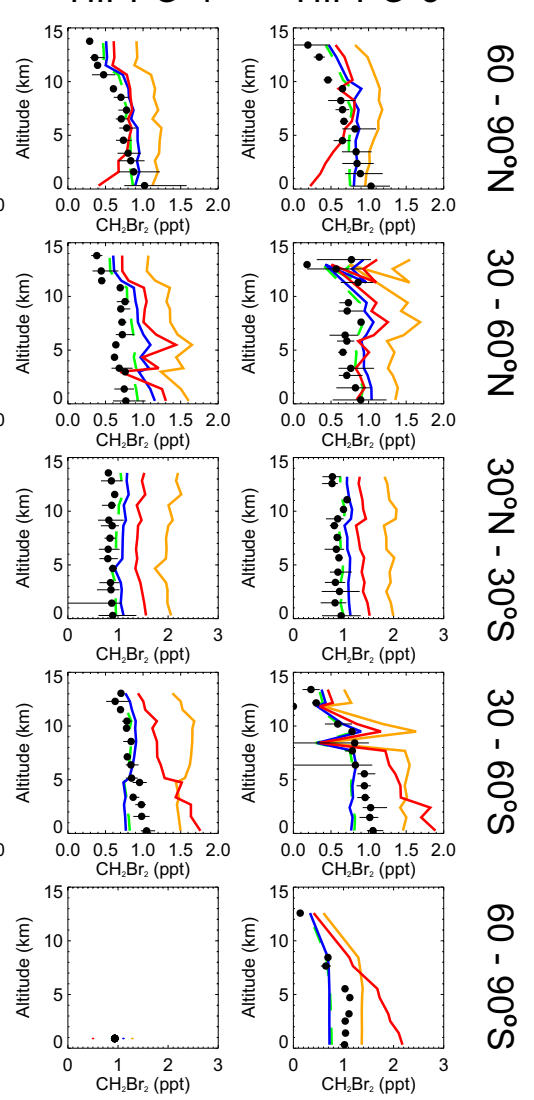

$\omega$
0
1
o
$z$
$z$

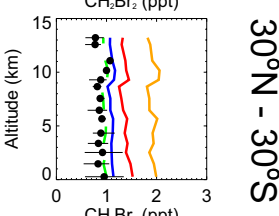

$\omega$
0
2
1
0
0
$\omega$
$\omega$
0
1
8
0
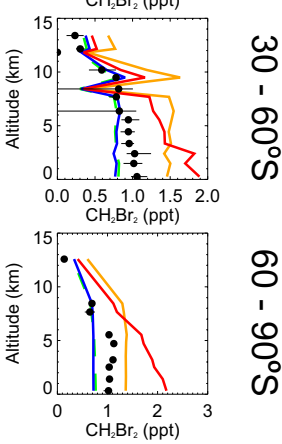

8
1
0
0
1

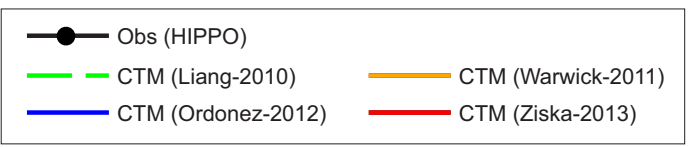

Fig. 8. As Fig. 7 but for $\mathrm{CH}_{2} \mathrm{Br}_{2}$.

$\mathrm{CHBr}_{3}$ in the tropics, suggesting overestimated emissions in this region from the top-down inventories.

The model is also able to reproduce the observed distribution of $\mathrm{CH}_{2} \mathrm{Br}_{2}$ well. Again, the overall skill of the model is highly dependent on the given emission inventory. For each of the 5 latitude bands considered, the best agreement between the model and observation is obtained from run $S_{\text {Liang }}$. The calculated MAPE for this run is $<25 \%$ within each lat- itude band and globally is $\sim 18 \%$. This supports the findings of the ground-based analysis presented in Sect. 3, where the Liang-2010 emission inventory, which has the lowest total emissions of $62 \mathrm{Gg} \mathrm{CH}_{2} \mathrm{Br}_{2} \mathrm{yr}^{-1}$ (Table 1), was shown to perform particularly well. Note, the Ordóñez-2012 inventory also performs well for $\mathrm{CH}_{2} \mathrm{Br}_{2}$ with a global MAPE of $\sim 24 \%$. This is a significantly better agreement that than obtained from the Warwick-2011 (87\%) and Ziska-2013 
inventories $(63 \%)$ that generally lead to overestimation of $\mathrm{CH}_{2} \mathrm{Br}_{2}$. Overall, for both $\mathrm{CHBr}_{3}$ and $\mathrm{CH}_{2} \mathrm{Br}_{2}$ the calculated biases between the model and the HIPPO aircraft data are consistent with, and support the findings of, the comparisons with the NOAA/ESRL ground-based observations.

\section{A case study in the tropical western Pacific}

The tropical western Pacific is a region of frequent and intense convection resulting in efficient transport of boundary layer air into the tropical tropopause layer (TTL) (e.g. Fueglistaler et al., 2009; Krug̈er et al., 2009). A number of model studies have reported the importance of the tropical western Pacific for the transport of VSLS into the stratosphere (e.g. Levine et al., 2007; Aschmann et al., 2009). The region is poorly sampled and local emissions, including those from farmed seaweed species (Leedham et al., 2013), are uncertain. Previous regional observations of VSLS include those made during the OP3 campaign on Borneo (Pyle et al., 2011). Background $\mathrm{CHBr}_{3}$ was reported at $\sim 1 \mathrm{ppt}$ inland (Danum Valley) with a larger background (2-5 ppt) reported along the coast (Kunak).

Figure 9 shows the modelled 2011 mean surface mixing ratio of $\mathrm{CHBr}_{3}$ over the tropical western Pacific. Different emission inventories lead to significant variation between the modelled $\mathrm{CHBr}_{3}$ abundance. The largest modelled $\mathrm{CHBr}_{3}$ in this region is from $S_{\text {Liang }}$ and $S_{\text {Ordonez }}$ with $\sim 3.25$ and $3.0 \mathrm{ppt}$ around the northern coast of Borneo. These emission inventories were derived with little or no observations in the tropical western Pacific (see Liang et al., 2010; and Ordóñez et al., 2012). Runs $S_{\text {Warwick }}$ and $S_{\text {Ziska }}$ show significantly lower $\mathrm{CHBr}_{3}(\sim 2 \mathrm{ppt})$ and this is likely due to the use of regional observations in the formulation of these inventories. Warwick-2011 was derived with regional scaling to give good agreement with observations made during OP3 on Borneo, while Ziska-2013, the bottom-up estimate, included $\mathrm{CHBr}_{3}$ sea-air flux data measured in this region during the Trans-Brom cruise (Krüger and Quack, 2013). For surface $\mathrm{CH}_{2} \mathrm{Br}_{2}$ (also Fig. 9), the modelled mixing ratio is typically between $\sim 1.0$ and $1.5 \mathrm{ppt}$ in the region of Borneo for all runs. The exception is run $S_{\text {Warwick, }}$, where it is $\sim 1$ ppt greater (i.e. $\sim 2.0-2.5 \mathrm{ppt}$ ) due to the larger regional emissions in the Warwick-2011 inventory. The remainder of Sect. 5 evaluates the CTM and emission inventories in this region using recent aircraft observations made in the free troposphere during the 2011 SHIVA campaign.

\subsection{The 2011 SHIVA campaign}

The SHIVA campaign is a European Union (EU) funded research project (http://shiva.iup.uni-heidelberg.de/). A primary SHIVA objective is to investigate biogenic emissions of VSLS, their atmospheric transformation, transport to the stratosphere and ultimately their impact on $\mathrm{O}_{3}$. A field cam-
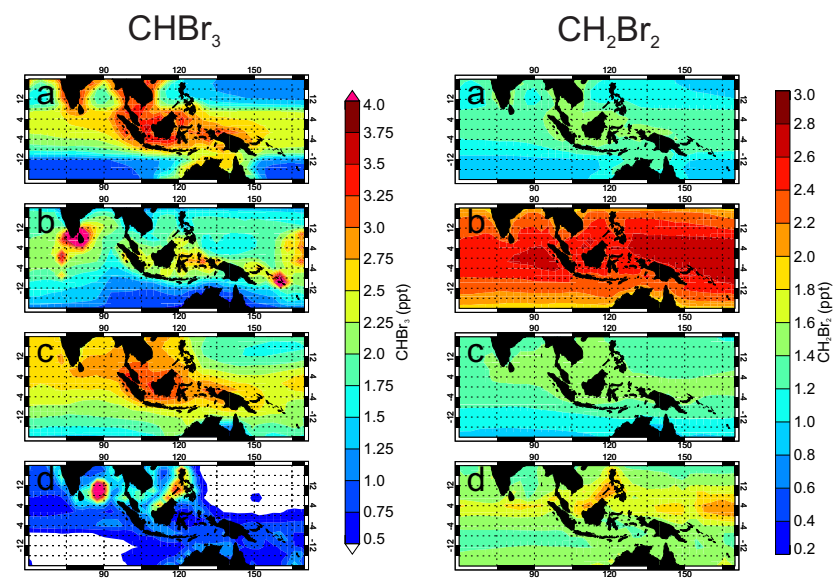

Fig. 9. Modelled mean surface mixing ratio (ppt) of $\mathrm{CHBr}_{3}$ (left column) and $\mathrm{CH}_{2} \mathrm{Br}_{2}$ (right column) over the tropical western Pacific during 2011 for CTM runs (a) $S_{\text {Liang }}$, (b) $S_{\text {Warwick, }}$ (c) $S_{\text {Ordonez }}$ and (d) $S_{\text {Ziska }}$.

paign was conducted during November-December 2011 in the tropical western Pacific region based on Malaysian Borneo. An overview of the campaign is given in Pfeilsticker and the SHIVA consortium (2013).

\subsubsection{Aircraft observations}

Aircraft observations of VSLS in the tropical western Pacific region are extremely limited. Within the framework of SHIVA, aircraft observations of brominated VSLS were made during 14 flights on board the Deutschen Zentrums für Luft- und Raumfahrt (DLR) Falcon aircraft around Borneo. The flight tracks and location of sampling is shown in Fig. 10. Here we consider observations of major VSLS $\mathrm{CHBr}_{3}$ and $\mathrm{CH}_{2} \mathrm{Br}_{2}$ made by the University of Frankfurt (UOF) and the University of East Anglia (UEA). These data are used to further evaluate the performance of the model, and top-down/bottom-up emission inventories, in the free troposphere within this poorly sampled region.

Observations made by the UOF group used the Gas chromatograph for Observation of Stratospheric Tracers-Mass Spectrometer (GhOST-MS) instrument - a fully automated GC/MS system for airborne (in situ) observations of halogenated hydrocarbons. Observed mixing ratios for $\mathrm{CHBr}_{3}$ and $\mathrm{CH}_{2} \mathrm{Br}_{2}$ from the GhOST-MS are reported on the NOAA-2003 calibration scale (see Sects. 3 and 4). The determined accuracy of the working standard gas is estimated at 16.5 and $9.0 \%$ for these species, respectively. The precision of the instrument varies between flights but is typically $<4 \%$ for both species. For further details of the SHIVA aircraft observations see Sala et al. (2013).

Observations by UEA used the Falcon's whole air sampler (WASP) that consisted of 30 glass flasks (approximately $700 \mathrm{~mL}$ internal volume) which were filled to a pressure of 2.5 Bar using a diaphragm pump. The samples were analysed 


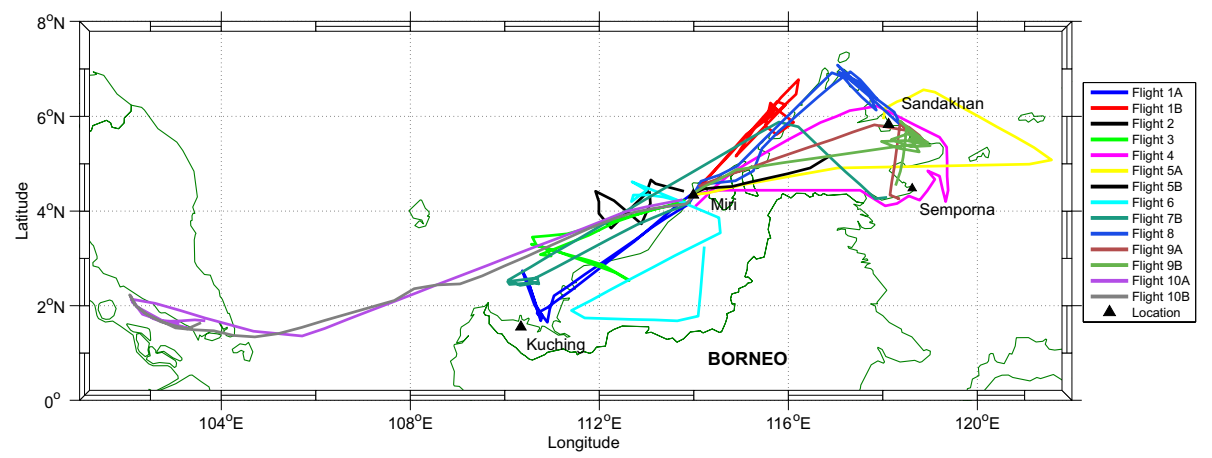

Fig. 10. Flight tracks of the DLR Falcon aircraft during November and December 2011 as part of the 2011 SHIVA campaign.

for halocarbons within $48 \mathrm{~h}$ of collection using a GC/MS (Agilent 6973) operating in negative ion, chemical ionisation mode (Worton et al., 2008). Because of a limitation of the sampling pump, WASP samples were only collected at altitudes below $\sim 3 \mathrm{~km}$. WASP data for $\mathrm{CHBr}_{3}$ and $\mathrm{CH}_{2} \mathrm{Br}_{2}$ are also reported on the most recent NOAA scales. Typical analytical precision $(750 \mathrm{~mL}$ sample) was $<4 \%$ for both compounds, with a calibration uncertainty of 7.1 and $6.5 \%$ for $\mathrm{CHBr}_{3}$ and $\mathrm{CH}_{2} \mathrm{Br}_{2}$, respectively. The two bromocarbon data sets will be examined in further detail in Sala et al. (2013).

Figure 11 shows the modelled mixing ratio of $\mathrm{CHBr}_{3}$ sampled along the flight track of the Falcon aircraft during SHIVA. Also shown is the observed $\mathrm{CHBr}_{3}$ mixing ratio from the GhOST-MS and WASP instruments. The observations show that during most flights, $\mathrm{CHBr}_{3}$ rarely exceed $1.0-1.5$ ppt. A notable exception is flight 4 , during which $\mathrm{CHBr}_{3}$ was elevated (> $2 \mathrm{ppt}$ ) near the surface. Large quantities of seaweed were visible from the aircraft during this flight, suggesting a large and localised emission source. Note, within the framework of SHIVA, emissions of halocarbons from both naturally occurring, and farmed tropical macroalgae, has been investigated (Leedham et al., 2013).

The agreement between modelled and observed $\mathrm{CHBr}_{3}$ is highly dependent on the emission inventory. As before, we have calculated the MB (ppt), the MAD (ppt) and the MAPE (\%) between the model and observation for all flights considered. For $\mathrm{CHBr}_{3}$, a summary of these metrics is given in Table 7. In general, the top-down inventories (Liang-2010, Warwick-2011, and Ordóñez-2012) overestimate the observations. This is particularly the case for runs $S_{\text {Liang }}$ and $S_{\text {Ordonez }}$ where $\mathrm{CHBr}_{3}$ is overestimated, from the surface up to $\sim 12 \mathrm{~km}$, during numerous flights (e.g. flights $2 \mathrm{a}, 7,10 \mathrm{~b}$ ). The MB between model and observation for these flights is $1.67,1.32$ and $0.96 \mathrm{ppt}$ for $S_{\text {Liang }}$ and 1.61, 1.19and $0.99 \mathrm{ppt}$ for $S_{\text {Ordonez }}$. Whilst also overestimating, an improved agreement is obtained from run $S_{\text {Warwick }}$ in this region. For example, for the same flights the MB is smaller (i.e. $\mathrm{MB}<1 \mathrm{ppt}$ ) at $0.82,0.78$, and $0.47 \mathrm{ppt}$. Overall, the best agreement is obtained from $S_{\text {Ziska }}$ (bottom-up emissions), which for some flights exhibits a small negative bias. For the above flights, the $\mathrm{MB}$ from this run is $0.31,0.06$ and $0.07 \mathrm{ppt}$, respectively.

Across all the flights considered, the MAPE between the model and observed $\mathrm{CHBr}_{3}$ is $117,68,125$ and $37 \%$ for runs $S_{\text {Liang }}, S_{\text {Warwick }}, S_{\text {Ordonez }}$ and $S_{\text {Ziska }}$, respectively - highlighting the significant variation in the performance of the inventories in this region. The bottom-up $\mathrm{CHBr}_{3}$ emissions proposed by Ziska et al. (2013) perform particularly well as this is the only inventory that gives rise to a MAPE $<50 \%$ in this region. This inventory was also shown to perform well against the NOAA/ESRL ground-based observations (Sect. 3) and HIPPO aircraft observations (Sect. 4) in the tropical Pacific Basin. The Ziska-2013 inventory is constrained by local sea-to-air fluxes obtained in the tropical western Pacific during ship cruises; e.g. Trans-Brom (Krüger and Quack, 2013). This is the likely explanation as to why the MAPE is significantly lower for this inventory, over Liang-2010 and Ordóñez-2012, that are based on limited or no regional (aircraft) observations. The same is true of the Warwick-2011 inventory, which also performs relatively well in this region, and is constrained by local (ground-based) observations. This further highlights the need for more local observations of VSLS, particularly in poorly sampled regions, in order to improve VSLS emission inventories at the regional scale.

Figure 12 shows the modelled versus observed $\mathrm{CH}_{2} \mathrm{Br}_{2}$ during SHIVA flights. The observations show $\mathrm{CH}_{2} \mathrm{Br}_{2}$ typically in the range of $0.5-1.5 \mathrm{ppt}$ during most flights and with a relatively small vertical gradient. The performance of each emission inventory is assessed using the error metrics summarised in Table 8. Across all flights, the MAPE is relatively low (compared with that for $\mathrm{CHBr}_{3}$ ) at 25, 119, 34 and $56 \%$ for runs $S_{\text {Liang }}, S_{\text {Warwick }}, S_{\text {Ordonez }}$ and $S_{\text {Ziska }}$, respectively. Consistent with the NOAA/ESRL ground-based analysis (Sect. 3) and also the HIPPO aircraft analysis (Sect. 4), the best agreement (diagnosed by lowest MAPE) between modelled and observed $\mathrm{CH}_{2} \mathrm{Br}_{2}$, is obtained by $S_{\text {Liang. }}$. For run $S_{\text {Warwick, }}$, which was previously shown to overestimate surface $\mathrm{CH}_{2} \mathrm{Br}_{2}$ at NOAA/ESRL stations in the Pacific Basin (e.g. Fig. 6), we again find an overestimate against SHIVA 
Table 7. Summary of calculated error metrics between $\mathrm{CHBr}_{3}$ observed in the free troposphere during 14 flights of the SHIVA aircraft campaign (November-December 2011) with analogous fields from CTM runs $S_{\text {Liang }}, S_{\text {Warwick }}, S_{\text {Ordonez }}$ and $S_{\text {Ziska }}$. Shown is the MB and the MAD both in units of ppt. Also shown is the MAPE (see text). These fields were calculated for all observations from both instruments deployed during SHIVA (i.e. GhOST-MS and WASP, see text). A mean value for all 14 flights is also reported.

\begin{tabular}{|c|c|c|c|c|c|c|c|c|c|c|c|c|}
\hline \multirow[t]{2}{*}{ Flight } & \multicolumn{3}{|c|}{ Run $S_{\text {Liang }}$} & \multicolumn{3}{|c|}{ Run $S_{\text {Warwick }}$} & \multicolumn{3}{|c|}{ Run $S_{\text {Ordonez }}$} & \multicolumn{3}{|c|}{ Run $S_{\text {Ziska }}$} \\
\hline & $\mathrm{MB}$ & MAD & MAPE & $\mathrm{MB}$ & MAD & MAPE & $\mathrm{MB}$ & MAD & MAPE & MB & MAD & MAPE \\
\hline $2 a$ & 1.67 & 1.67 & $192 \%$ & 0.82 & 0.82 & $99 \%$ & 1.61 & 1.61 & $187 \%$ & 0.31 & 0.39 & $46 \%$ \\
\hline $2 b$ & 0.58 & 0.58 & $101 \%$ & 0.43 & 0.43 & $77 \%$ & 0.70 & 0.70 & $122 \%$ & -0.08 & 0.16 & $24 \%$ \\
\hline 3 & 0.49 & 0.61 & $40 \%$ & -0.20 & 0.34 & $22 \%$ & 0.55 & 0.62 & $44 \%$ & 0.34 & 0.58 & $35 \%$ \\
\hline 4 & 0.70 & 0.70 & $82 \%$ & 0.25 & 0.31 & $42 \%$ & 0.84 & 0.85 & $101 \%$ & 0.13 & 0.27 & $32 \%$ \\
\hline 5 & 0.43 & 0.53 & $67 \%$ & 0.04 & 0.41 & $51 \%$ & 0.55 & 0.63 & $80 \%$ & -0.76 & 0.79 & $48 \%$ \\
\hline $6 a$ & 0.42 & 0.57 & $122 \%$ & 0.18 & 0.42 & $84 \%$ & 0.48 & 0.59 & $127 \%$ & -0.28 & 0.35 & $39 \%$ \\
\hline $6 b$ & 0.62 & 0.75 & $113 \%$ & 0.26 & 0.43 & $65 \%$ & 0.73 & 0.87 & $127 \%$ & -0.07 & 0.27 & $28 \%$ \\
\hline 7 & 1.32 & 1.32 & $308 \%$ & 0.78 & 0.78 & $186 \%$ & 1.19 & 1.19 & $277 \%$ & 0.06 & 0.20 & $39 \%$ \\
\hline $8 b$ & 0.81 & 0.81 & $120 \%$ & 0.33 & 0.35 & $62 \%$ & 0.86 & 0.86 & $128 \%$ & -0.08 & 0.20 & $28 \%$ \\
\hline 9 & 0.56 & 0.59 & $91 \%$ & 0.36 & 0.43 & $68 \%$ & 0.70 & 0.71 & $109 \%$ & -0.23 & 0.28 & $34 \%$ \\
\hline $10 \mathrm{a}$ & 1.01 & 1.01 & $150 \%$ & 0.40 & 0.41 & $74 \%$ & 1.03 & 1.03 & $155 \%$ & 0.18 & 0.29 & $40 \%$ \\
\hline $10 \mathrm{~b}$ & 0.96 & 0.96 & $172 \%$ & 0.47 & 0.49 & $106 \%$ & 0.99 & 0.99 & $178 \%$ & 0.07 & 0.25 & $40 \%$ \\
\hline $11 \mathrm{a}$ & 0.45 & 0.57 & $77 \%$ & -0.02 & 0.43 & $47 \%$ & 0.65 & 0.71 & $92 \%$ & -0.50 & 0.54 & $37 \%$ \\
\hline $11 \mathrm{~b}$ & 0.49 & 0.59 & $78 \%$ & -0.01 & 0.38 & $43 \%$ & 0.70 & 0.74 & $95 \%$ & -0.42 & 0.46 & $34 \%$ \\
\hline All & 0.76 & 0.81 & $117 \%$ & 0.28 & 0.46 & $68 \%$ & 0.84 & 0.87 & $125 \%$ & -0.12 & 0.39 & $37 \%$ \\
\hline
\end{tabular}

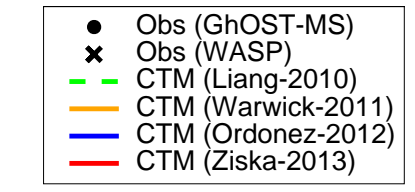

Flight $3(21 / 11 / 11)$
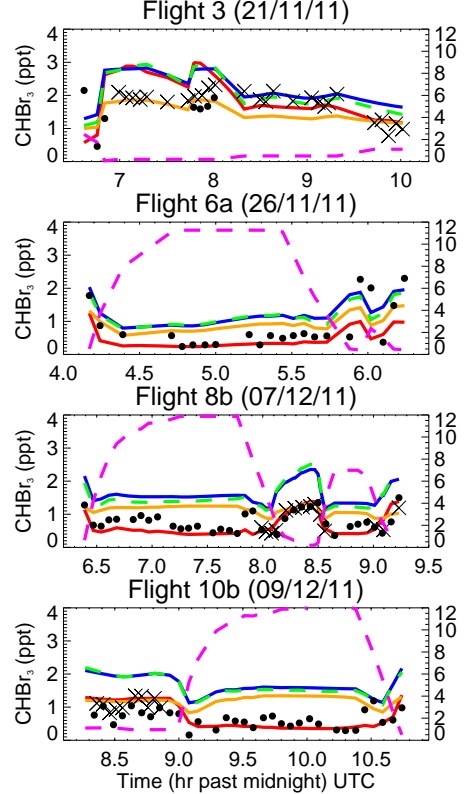
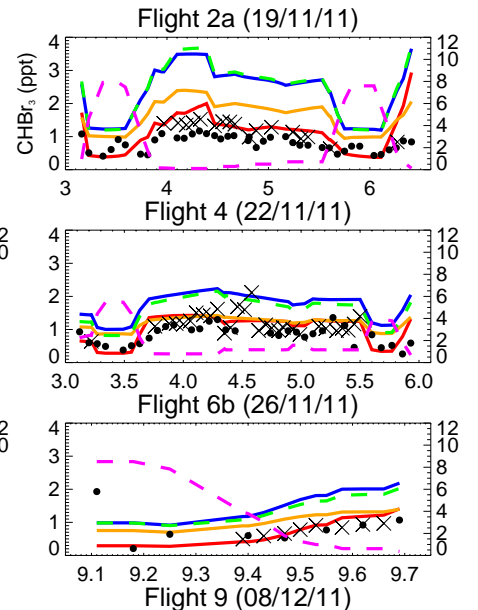

Flight $9(08 / 12 / 11)$

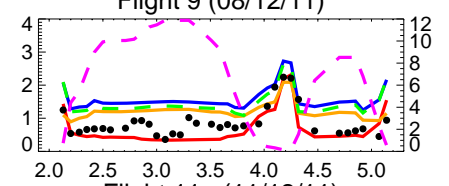

Flight 11a $(11 / 12 / 11)$

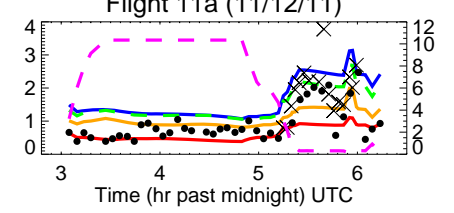

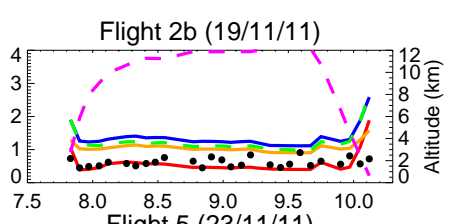
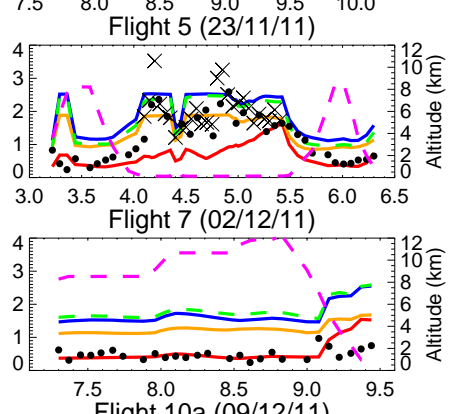

Flight 10a $(09 / 12 / 11)$

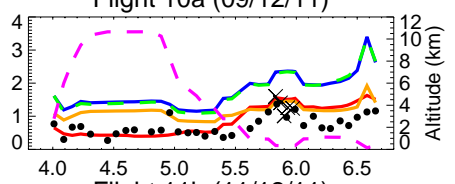

Flight $11 \mathrm{~b}(11 / 12 / 11)$

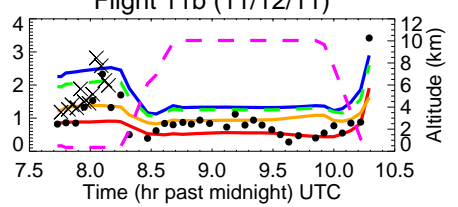

Fig. 11. Comparison between modelled and observed $\mathrm{CHBr}_{3}$ mixing ratio (ppt) along the flight tracks of the DLR Falcon aircraft during the 2011 SHIVA campaign. Model output is from CTM runs $S_{\text {Liang }}, S_{\text {Warwick }}, S_{\text {Ordonez }}$ and $S_{\text {Ziska }}$ and observed data from the GhOST in situ GC/MS system and the WASP whole air sampler (Sala et al., 2013). The dashed pink line denotes the altitude of the aircraft. 
Table 8. As Table 7 but for $\mathrm{CH}_{2} \mathrm{Br}_{2}$.

\begin{tabular}{lrrr|rrr|rrr|rr|rr}
\hline \multirow{2}{*}{ Flight } & \multicolumn{3}{c|}{ Run $S_{\text {Liang }}$} & \multicolumn{3}{c|}{ Run $S_{\text {Warwick }}$} & \multicolumn{3}{c|}{ Run $S_{\text {Ordonez }}$} & \multicolumn{3}{c}{ Run $S_{\text {Ziska }}$} \\
\cline { 2 - 13 } & MB & MAD & MAPE & MB & MAD & MAPE & MB & MAD & MAPE & MB & MAD & MAPE \\
\hline 2a & 0.38 & 0.42 & $45 \%$ & 1.23 & 1.23 & $134 \%$ & 0.45 & 0.48 & $52 \%$ & 0.64 & 0.65 & $70 \%$ \\
2b & 0.16 & 0.16 & $20 \%$ & 1.14 & 1.14 & $133 \%$ & 0.27 & 0.27 & $32 \%$ & 0.49 & 0.49 & $58 \%$ \\
3 & 0.12 & 0.13 & $13 \%$ & 1.08 & 1.08 & $102 \%$ & 0.23 & 0.23 & $23 \%$ & 0.66 & 0.66 & $62 \%$ \\
4 & 0.22 & 0.22 & $26 \%$ & 1.08 & 1.08 & $125 \%$ & 0.34 & 0.34 & $40 \%$ & 0.57 & 0.57 & $65 \%$ \\
5 & 0.04 & 0.12 & $12 \%$ & 0.90 & 0.90 & $89 \%$ & 0.15 & 0.17 & $18 \%$ & 0.22 & 0.24 & $25 \%$ \\
$6 \mathrm{a}$ & 0.13 & 0.20 & $25 \%$ & 1.00 & 1.00 & $124 \%$ & 0.21 & 0.25 & $31 \%$ & 0.37 & 0.38 & $49 \%$ \\
$6 \mathrm{~b}$ & 0.17 & 0.17 & $21 \%$ & 0.97 & 0.97 & $115 \%$ & 0.27 & 0.27 & $32 \%$ & 0.41 & 0.41 & $49 \%$ \\
7 & 0.46 & 0.46 & $62 \%$ & 1.49 & 1.49 & $200 \%$ & 0.50 & 0.50 & $68 \%$ & 0.75 & 0.75 & $101 \%$ \\
$8 \mathrm{~b}$ & 0.20 & 0.20 & $24 \%$ & 1.07 & 1.07 & $125 \%$ & 0.30 & 0.30 & $35 \%$ & 0.52 & 0.52 & $61 \%$ \\
9 & 0.12 & 0.13 & $15 \%$ & 1.13 & 1.13 & $125 \%$ & 0.25 & 0.25 & $29 \%$ & 0.59 & 0.59 & $65 \%$ \\
$10 \mathrm{a}$ & 0.26 & 0.26 & $29 \%$ & 1.10 & 1.10 & $126 \%$ & 0.35 & 0.35 & $40 \%$ & 0.57 & 0.57 & $65 \%$ \\
$10 \mathrm{~b}$ & 0.25 & 0.26 & $32 \%$ & 1.18 & 1.18 & $139 \%$ & 0.35 & 0.35 & $42 \%$ & 0.65 & 0.65 & $77 \%$ \\
$11 \mathrm{a}$ & 0.05 & 0.18 & $18 \%$ & 0.88 & 0.88 & $94 \%$ & 0.17 & 0.21 & $23 \%$ & 0.27 & 0.30 & $34 \%$ \\
$11 \mathrm{~b}$ & 0.06 & 0.13 & $14 \%$ & 0.89 & 0.89 & $92 \%$ & 0.19 & 0.19 & $21 \%$ & 0.30 & 0.31 & $33 \%$ \\
All & 0.18 & 0.22 & $25 \%$ & 1.07 & 1.07 & $119 \%$ & 0.28 & 0.29 & $34 \%$ & 0.49 & 0.49 & $56 \%$ \\
\hline
\end{tabular}
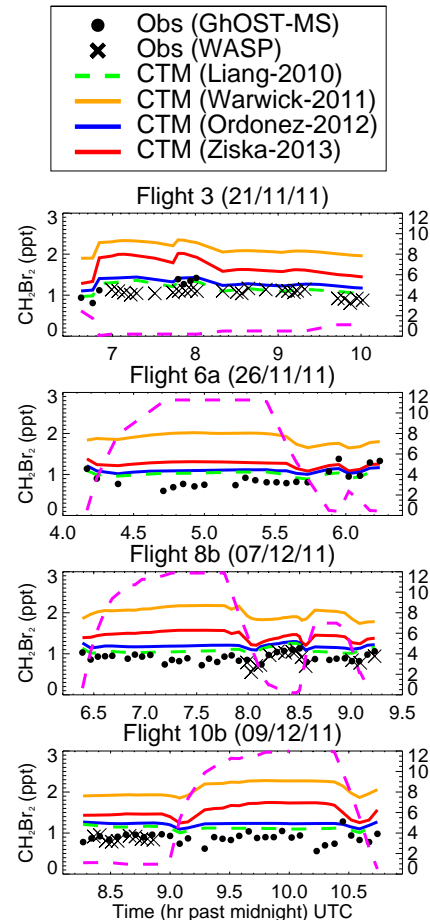
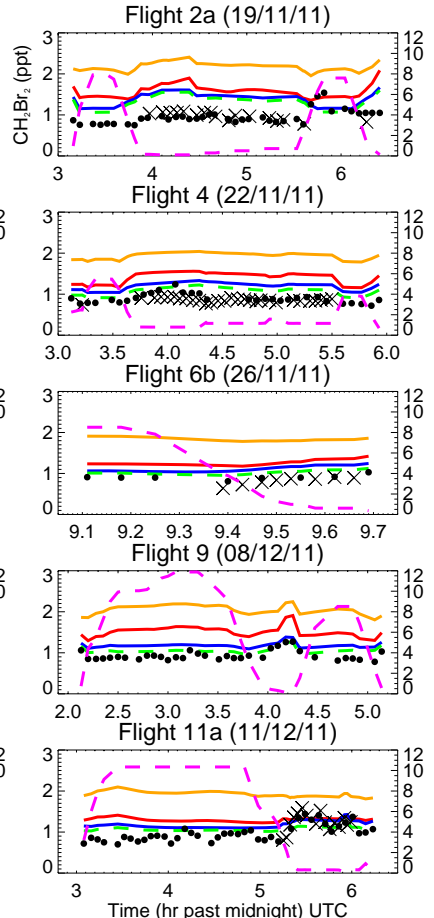
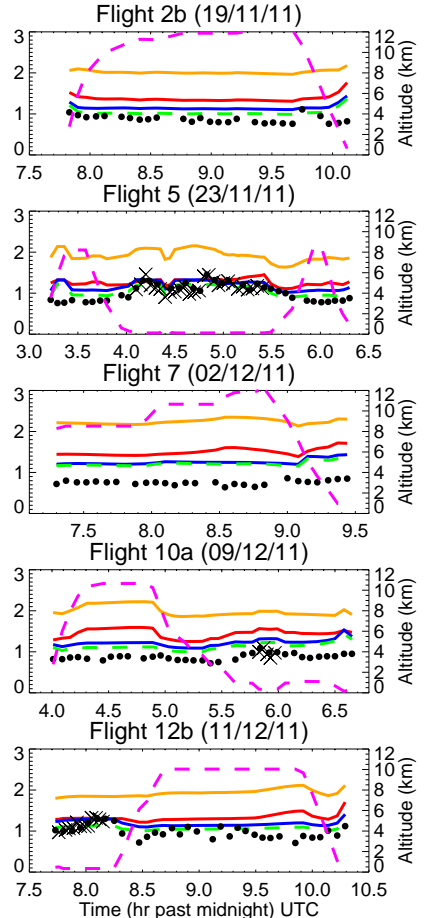

Fig. 12. As Fig. 11 but for $\mathrm{CH}_{2} \mathrm{Br}_{2}$.

observations (approximate factor of 2). Therefore, it seems highly likely that the $\mathrm{CH}_{2} \mathrm{Br}_{2}$ emission strength is significantly overestimated in the tropics by the Warwick-2011 inventory.

\section{Sensitivity of stratospheric bromine loading to emission inventory}

In our previous modelling work, emissions of major VSLS $\mathrm{CHBr}_{3}$ and $\mathrm{CH}_{2} \mathrm{Br}_{2}$ were not specified in the TOMCAT CTM (Hossaini et al., 2010, 2012b). Rather, a uniform surface mixing ratio $(\sim 1.2 \mathrm{ppt})$ was imposed in the tropics $\left( \pm 20^{\circ}\right)$ based on compiled aircraft observations. Using this 
approach, Hossaini et al. (2012b) quantified stratospheric $\mathrm{Br}_{\mathrm{y}}^{\mathrm{VSLS}}$ as $\sim 5 \mathrm{ppt}$; i.e. within the compiled range of $1-8 \mathrm{ppt}$ outlined in WMO (2011), and in general agreement with balloon-borne estimates (Dorf et al., 2006, 2008). The CTM performed reasonably well against aircraft observations in the TTL. However, this approach meant regional hot-spots, where emissions may be large and background concentrations elevated, were not captured. Any dependence of stratospheric $\mathrm{Br}_{\mathrm{y}}^{\mathrm{VSLS}}$ on the spatial distribution of surface emissions was also not modelled. Here, using the CTM runs presented in this paper (i.e. multiple emission inventories for $\mathrm{CHBr}_{3}$ and $\mathrm{CH}_{2} \mathrm{Br}_{2}$ ), we revise our estimate of $\mathrm{Br}_{\mathrm{y}}^{\mathrm{VSLS}}$ based on these spatially varying, and seasonally varying in the case of Ordóñez-2012, emission inventories.

It is thought that VSLS contribute to the stratospheric bromine budget via both source gas injection (SGI) and also product gas injection (PGI). The SGI pathway is quantified by summing the total organic bromine from VSLS reaching the lower stratosphere. For PGI, which refers to the troposphere-stratosphere transport of inorganic product gases (e.g. $\mathrm{BrO}, \mathrm{HBr}$ ), the tropospheric partitioning of $\mathrm{Br}_{\mathrm{y}}$ among soluble and non-soluble species needs consideration. As this involves complex heterogeneous and multi-phase processes (e.g. Aschmann and Sinnhuber, 2013), which are crudely treated in global models, $\mathrm{Br}_{\mathrm{y}}$ speciation and recycling represents a significant uncertainty in the quantification of PGI with models. The approach used here is identical to that described in Hossaini et al. (2012b). Once $\mathrm{Br}_{\mathrm{y}}$ is released from source gases it is partitioned between soluble and non-soluble form according to a mean altitude-dependent $\mathrm{HBr}: \mathrm{Br}_{\mathrm{y}}$ ratio. This was taken from a previous CTM integration in which detailed partitioning of tropospheric $\mathrm{Br}_{\mathrm{y}}$ was considered.

Figure 13 shows the modelled tropical mean profile of $\mathrm{Br}_{\mathrm{y}}^{\mathrm{VSLS}}$ in the stratosphere at the end of the $14 \mathrm{yr}$ simulation. We find $\mathrm{Br}_{\mathrm{y}}^{\mathrm{VSLS}}$ ranges from $\sim 5$ to 8 ppt (above $\sim 30 \mathrm{~km}$ ) depending on the choice of emission inventory. Runs $S_{\text {Ziska }}$ and $S_{\text {Warwick }}$ account for the lower limit and upper limit, respectively. However, as $S_{\text {Warwick }}$ overestimated both $\mathrm{CHBr}_{3}$ and $\mathrm{CH}_{2} \mathrm{Br}_{2}$ significantly in the tropics, it seems likely that the upper limit of $\sim 8$ ppt reported here is also an overestimate. We have therefore now identified a range of uncertainty with regard to emissions of major VSLS $\mathrm{CHBr}_{3}$ and $\mathrm{CH}_{2} \mathrm{Br}_{2}$ on stratospheric $\mathrm{Br}_{\mathrm{y}}^{\mathrm{VSLS}}$ loading. Note, here $\mathrm{Br}_{\mathrm{y}}^{\mathrm{VSLS}}$ also includes the contribution from minor VSLS $\mathrm{CHBr}_{2} \mathrm{Cl}$, $\mathrm{CHBrCl}_{2}$ and $\mathrm{CH}_{2} \mathrm{BrCl}$. Their total contribution to $\mathrm{Br}_{\mathrm{y}}^{\mathrm{VSLS}}$ is $\sim 1 \mathrm{ppt}$ and is consistent between each model run.

The modelled stratospheric $\mathrm{Br}_{\mathrm{y}}^{\mathrm{VSLS}}$ ranges from $\sim 5$ to 8 ppt when both $\mathrm{CHBr}_{3}$ and $\mathrm{CH}_{2} \mathrm{Br}_{2}$ are taken from the same inventory. However, in the tropics, where the tropospherestratosphere transport of VSLS is most rapid, it was shown using ground-based (Sect. 3) and aircraft (Sect. 4) observations that a single inventory does not provide the simultaneous best agreement for both VSLS in this region. For $\mathrm{CHBr}_{3}$,

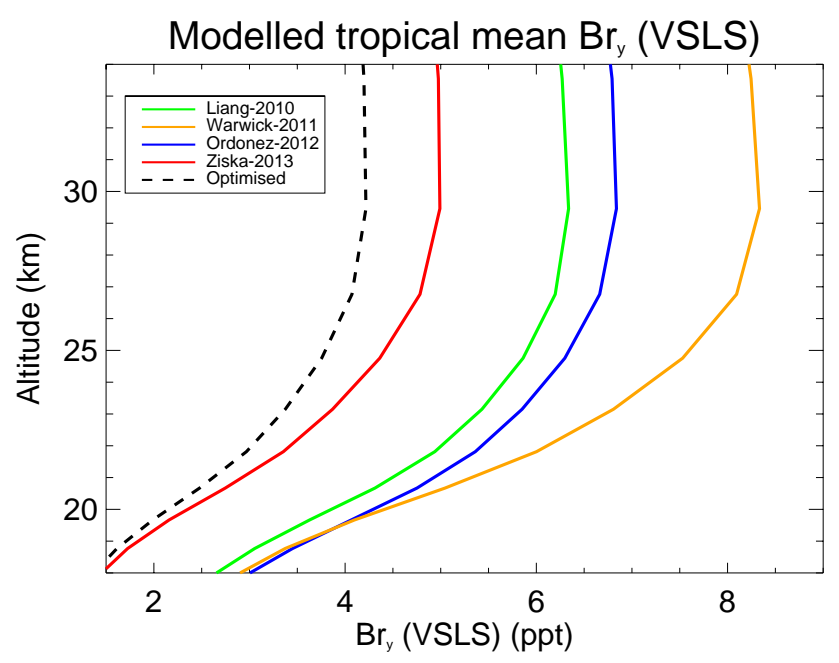

Fig. 13. Modelled 2011 tropical $\left( \pm 30^{\circ}\right)$ mean profile of total inorganic bromine (ppt) from $\mathrm{CHBr}_{3}, \mathrm{CH}_{2} \mathrm{Br}_{2}, \mathrm{CHBr}_{2} \mathrm{Cl}, \mathrm{CH}_{2} \mathrm{BrCl}$ and $\mathrm{CHBrCl}_{2}\left(\mathrm{Br}_{\mathrm{y}}^{\mathrm{VSLS}}\right)$ in the stratosphere. Profiles are shown for CTM runs $S_{\text {Liang }}, S_{\text {Warwick }}, S_{\text {Ordonez }}$, and $S_{\text {Ziska }}$. An optimised estimate, calculated by combining $\mathrm{CHBr}_{3}$ from $\mathrm{S}_{\text {Ziska }}$ and $\mathrm{CH}_{2} \mathrm{Br}_{2}$ from $S_{\text {Liang }}$, is also shown.

the best agreement was obtained from run $S_{\text {Ziska }}$ and similarly, for $\mathrm{CH}_{2} \mathrm{Br}_{2}$, run $S_{\text {Liang }}$ gave the best agreement. Therefore, we also report an optimised estimate of stratospheric $\mathrm{Br}_{\mathrm{y}}^{\mathrm{VSLS}}$ based on a combination of these two fields; $\sim 4 \mathrm{ppt}$ (also shown in Fig. 13). From the 4 inventories considered, the $\mathrm{CHBr}_{3}$ and $\mathrm{CH}_{2} \mathrm{Br}_{2}$ source strengths are the lowest in Ziska-2013 and Liang-2010, respectively. Therefore, the optimised estimate reported here is lower than the range obtained when considering emissions of both species from the same inventory.

Our optimised $\mathrm{Br}_{\mathrm{y}}^{\mathrm{VSLS}}$ estimate of $\sim 4 \mathrm{ppt}$ is lower than that reported in our previous work ( $\sim 5 \mathrm{ppt}$ ) (Hossaini et al., $2012 b$ ), which did not use spatially varying emission fluxes. The use of a fixed mixing ratio as a surface boundary condition for $\mathrm{CHBr}_{3}$ and $\mathrm{CH}_{2} \mathrm{Br}_{2}$ in Hossaini et al. (2012b) may have overestimated their abundance in the boundary layer. However, our modelled optimised estimate is in good agreement with $\mathrm{Br}_{\mathrm{y}}^{\mathrm{VSLS}}$ derived from observations of stratospheric $\mathrm{BrO}$ (the so-called inorganic method). For example, using differential optical absorption spectroscopy (DOAS) to obtain $\mathrm{BrO}$ profiles, combined with photochemical modelling, Dorf et al. (2006) reported a $\mathrm{Br}_{\mathrm{y}}^{\mathrm{VSLS}}$ contribution of 4.1 $( \pm 2.5)$ ppt. However, given the recent findings of $\mathrm{Kr}-$ eycy et al. (2013) on the ratio of $J\left(\mathrm{BrONO}_{2}\right) / k\left(\mathrm{BrO}+\mathrm{NO}_{2}\right)$, this estimate may need to be revised downward. Overall, our model calculations are consistent with the broad $\mathrm{Br}_{\mathrm{y}}^{\mathrm{VSLS}}$ range of 1-8 ppt reported by WMO (2011). 


\section{Summary and conclusions}

Global models require a realistic treatment of biogenic bromine emissions in order to simulate a reasonable $\mathrm{Br}_{\mathrm{y}}$ budget in both the troposphere and the stratosphere. At present, oceanic emissions of brominated VSLS are poorly constrained and represent a significant uncertainty in global models (WMO, 2007, 2011). Given suggestions that stratospheric VSLS loading may increase in response to climate change (Dessens et al., 2009; Hossaini et al., 2012a), constraining both the magnitude and spatial distribution of contemporary emissions is important. In this study we have used a global model to perform the first concerted evaluation of previously published global $\mathrm{CHBr}_{3}$ and $\mathrm{CH}_{2} \mathrm{Br}_{2}$ emission inventories. We have evaluated three top-down and a bottomup derived inventory by comparing the simulated abundance of these VSLS with independent observations - i.e. the observed data was not included in the formulation of the emission inventories. The observed data have included long-term observations at various NOAA/ESRL ground-based stations, aircraft observations made during the NSF HIPPO campaigns (1-5) and also novel aircraft observations made during the 2011 SHIVA campaign over the poorly sampled tropical western Pacific. We have also updated our previous model estimate of $\mathrm{Br}_{\mathrm{y}}^{\mathrm{VSLS}}$ based on these available emission scenarios.

Our comparisons reveal the TOMCAT CTM is able to reproduce a variety of global $\mathrm{CHBr}_{3}$ and $\mathrm{CH}_{2} \mathrm{Br}_{2}$ observations. The agreement between the model and the observation is highly dependent on the choice of emission inventory, which differ significantly in terms of magnitude and spatial distribution. All the inventories considered give good agreement in some locations. However, to accurately diagnose the source gas injection of VSLS into the stratosphere, simulating their abundance in the tropics, where transport to the stratosphere is rapid, is most important. Comparison of the model with observations at NOAA/ESRL surface sites and also with aircraft observations obtained during HIPPO, shows a consistent pattern on the performance of individual emission inventories. Based on these comparisons, along with the results from the SHIVA case study, our main findings are the following.

- Current global emission inventories of $\mathrm{CHBr}_{3}$ and $\mathrm{CH}_{2} \mathrm{Br}_{2}$, which are used in global models, vary significantly. Evaluating these inventories is challenging due to the limited spatial coverage of long-term observations, particularly in the tropics and in the Southern Hemisphere. Averaged globally, the best agreement between modelled $\mathrm{CHBr}_{3}$ and $\mathrm{CH}_{2} \mathrm{Br}_{2}$ with longterm surface observations made by NOAA/ESRL is obtained using the top-down emissions proposed by Liang et al. (2010). Globally, the mean absolute percentage error between the model and NOAA/ESRL observations for this inventory is $\sim 50$ and $\sim 20 \%$ for
$\mathrm{CHBr}_{3}$ and $\mathrm{CH}_{2} \mathrm{Br}_{2}$ over a $14 \mathrm{yr}$ period, respectively. Comparison of the model with aircraft observations made during the HIPPO project, which spanned global latitudes over the Pacific Basin, also support these findings. Globally, the mean absolute percentage error between the model and HIPPO observations is similar at 42 and $18 \%$, for $\mathrm{CHBr}_{3}$ and $\mathrm{CH}_{2} \mathrm{Br}_{2}$ respectively, when using the Liang et al. (2010) emissions. Globally, we also find the $\mathrm{CH}_{2} \mathrm{Br}_{2}$ emissions of Ordóñez et al. (2012) perform particularly well with a mean absolute percentage error of less than $\sim 30 \%$ between model and observations.

- For $\mathrm{CHBr}_{3}$, within the tropics only, the best agreement between the model and observations is obtained using the bottom-up emission fluxes proposed by Ziska et al. (2013). Using this inventory, the mean absolute percentage error between the model and long-term NOAA/ESRL surface observations is $\sim 36 \%$. Against the HIPPO observations it is $\sim 35 \%$, with the other inventories considered giving a significantly larger bias (> $60 \%$ ). For $\mathrm{CH}_{2} \mathrm{Br}_{2}$, in the tropics the model is able to reproduce observations well using the Liang et al. (2010) emissions. The mean absolute percentage error is 24 and $16 \%$ when the model is compared with the NOAA/ESRL and HIPPO observations, respectively. Therefore, our results show the bias between model and observations is lowest when using the inventories that have the lowest tropical (and also total global) $\mathrm{CHBr}_{3}$ and $\mathrm{CH}_{2} \mathrm{Br}_{2}$ emission strength (i.e. Ziska and Liang, respectively)

- In the tropical western Pacific, where rapid troposphere-stratosphere transport coincides with relatively large VSLS emissions, the model is able to reproduce novel aircraft observations of $\mathrm{CHBr}_{3}$ and $\mathrm{CH}_{2} \mathrm{Br}_{2}$ made during the 2011 SHIVA campaign. The skill of the model is highly dependant on the choice of emission inventory. Good agreement is obtained for $\mathrm{CHBr}_{3}$ using the bottom-up emissions of Ziska et al. (2013). These emissions, along with the Warwick-2011 inventory, were formulated using local observations around Borneo and as such perform significantly better than inventories based on limited aircraft observations alone. Therefore, this further highlights the need for more observations of VSLS, particularly at a finer spatial resolution, in order to improve current regional emission estimates. For $\mathrm{CH}_{2} \mathrm{Br}_{2}$, which is a longer-lived source gas, the Liang et al. (2010) emissions were again found to give the best agreement with the observations.

- The modelled contribution of VSLS to stratospheric inorganic bromine varies significantly depending on the $\mathrm{CHBr}_{3}$ and $\mathrm{CH}_{2} \mathrm{Br}_{2}$ inventory used. We find $\mathrm{Br}_{\mathrm{y}}^{\mathrm{VSLS}}$ ranges from $\sim 5.0$ to $8.0 \mathrm{ppt}$ when using 
$\mathrm{CHBr}_{3}$ and $\mathrm{CH}_{2} \mathrm{Br}_{2}$ from the same inventory. However, we find no single inventory provides the simultaneous best agreement with observations in the tropics. Therefore, we also report an optimised estimate, calculated by combining the inventories which perform the best in this region. A combination of $\mathrm{CHBr}_{3}$ emissions from Ziska et al. (2013) and $\mathrm{CH}_{2} \mathrm{Br}_{2}$ emissions from Liang et al. (2010) lead to our (lower) optimised estimate of $\sim 4$ ppt. These inventories were found to consistently perform the best in the tropics using three independent sets of observations (i.e. NOAA/ESRL surface, HIPPO aircraft and SHIVA aircraft data). Both the modelled range and optimised estimate are within the compiled 1-8 ppt range reported by WMO (2011). Therefore, in this study we have now identified the range of uncertainty associated with emissions of major VSLS CHBr 3 and $\mathrm{CH}_{2} \mathrm{Br}_{2}$ on stratospheric $\mathrm{Br}_{\mathrm{y}}^{\mathrm{VSLS}}$ loading. Although, model estimates of the product gas injection contribution to $\mathrm{Br}_{\mathrm{y}}^{\mathrm{VSLS}}$ remain a significant uncertainty (e.g, Salawitch et al., 2010; Aschmann and Sinnhuber, 2013).

Our study has shown that in recent years understanding of oceanic VSLS emissions has improved significantly and that current inventories used in global models are reasonable. Based on the results of this work, it would be useful to revise current inventories and/or combine them to improve the treatment of $\mathrm{CHBr}_{3}$ and $\mathrm{CH}_{2} \mathrm{Br}_{2}$ emissions in global models. Furthermore, it would be useful for the analysis performed in this study to be repeated by other modelling groups, in order to determine the extent to which our results are model dependent. For example, to assess the role of differences in model transport, such as mixing in the boundary layer and convection, which are parameterised and likely to vary between models. A related exercise examining inter-model variability on the tropospheric distribution and the troposphere-stratosphere transport of VSLS is planned, within the framework of the ongoing Atmospheric Tracer Transport Model Inter comparison (TransCom) project (e.g. Patra et al., 2011). This project, TransCom-VSLS, will examine the performance of a number of global models against existing VSLS observations and also assess the variability between data sets, including the impact of temporal sampling and systematic biases on the agreement between models and observations. Finally, future work will examine emissions of relatively minor VSLS (e.g. $\mathrm{CHBr}_{2} \mathrm{Cl}, \mathrm{CH}_{2} \mathrm{BrCl}$ ) along with a more detailed examination of emission seasonality.

Acknowledgements. This work was supported by the UK Natural Environment Research Council (NERC) and the EU Stratospheric Ozone: Halogen Impacts in a Varying Atmosphere (SHIVA) project (SHIVA-226224-FP7-ENV-2008-1). TOMCAT work is suported by the National Centre for Atmospheric Science (NCAS). NOAA measurements were supported in part by NOAA's Atmospheric Chemistry, Carbon Cycle and Climate Program of its Climate
Program Office. Technical assistance, standardisation, and programmatic support for NOAA flask measurements was provided by C. Siso, B. Hall, and J. W. Elkins. The HIPPO project was supported by the National Science Foundation (NSF).

Edited by: J. Williams

\section{References}

Aschmann, J. and Sinnhuber, B.-M.: Contribution of very shortlived substances to stratospheric bromine loading: uncertainties and constraints, Atmos. Chem. Phys., 13, 1203-1219, doi:10.5194/acp-13-1203-2013, 2013.

Aschmann, J., Sinnhuber, B.-M., Atlas, E. L., and Schauffler, S. M.: Modeling the transport of very short-lived substances into the tropical upper troposphere and lower stratosphere, Atmos. Chem. Phys., 9, 9237-9247, doi:10.5194/acp-9-9237-2009, 2009.

Ashfold, M. J., Harris, N. R. P., Atlas, E. L., Manning, A. J., and Pyle, J. A.: Transport of short-lived species into the Tropical Tropopause Layer, Atmos. Chem. Phys., 12, 6309-6322, doi:10.5194/acp-12-6309-2012, 2012.

Beyersdorf, A. J., Blake, D. R., Swanson, A., Meinardi, S., Rowland, F. S., and Davis, D.: Abundances and variability of tropospheric volatile organic compounds at the South Pole and other Antarctic locations, Atmos. Environ., 44, 4565-4574, doi:10.1016/j.atmosenv.2010.08.025, 2010.

Breider, T. J., Chipperfield, M. P., Richards, N. A. D., Carslaw, K. S., Mann, G. W., and Spracklen, D. V.: Impact of BrO on dimethylsulfide in the remote marine boundary layer, Geophys. Res. Lett., 37, L02807, doi:10.1029/2009GL040868, 2010.

Brinckmann, S., Engel, A., Bönisch, H., Quack, B., and Atlas, E.: Short-lived brominated hydrocarbons - observations in the source regions and the tropical tropopause layer, Atmos. Chem. Phys., 12, 1213-1228, doi:10.5194/acp-12-1213-2012, 2012.

Carpenter, L. and Liss, P.: On temperate sources of bromoform and other reactive organic bromine gases, J. Geophys. Res.-Atmos., 105, 20539-20547, doi:10.1029/2000JD900242, 2000.

Carpenter, L. J., Wevill, D. J., O'Doherty, S., Spain, G., and Simmonds, P. G.: Atmospheric bromoform at Mace Head, Ireland: seasonality and evidence for a peatland source, Atmos. Chem. Phys., 5, 2927-2934, doi:10.5194/acp-5-2927-2005, 2005.

Chipperfield, M. P.: New version of the TOMCAT/SLIMCAT offline chemical transport model: Intercomparison of stratospheric tracer experiments, Q. J. Roy. Meteorol. Soc., 132, 1179-1203, doi:10.1256/qj.05.51, 2006.

Dessens, O., Zeng, G., Warwick, N., and Pyle, J.: Short-lived bromine compounds in the lower stratosphere; impact of climate change on ozone, Atmos. Sci. Lett., 10, 201-206, doi:10.1002/asl.236, 2009.

Dorf, M., Butler, J. H., Butz, A., Camy-Peyret, C., Chipperfield, M. P., Kritten, L., Montzka, S. A., Simmes, B., Weidner, F., and Pfeilsticker, K.: Long-term observations of stratospheric bromine reveal slow down in growth, Geophys. Res. Lett., 33, L24803, doi:10.1029/2006GL027714, 2006.

Dorf, M., Butz, A., Camy-Peyret, C., Chipperfield, M. P., Kritten, L., and Pfeilsticker, K.: Bromine in the tropical troposphere and stratosphere as derived from balloon-borne $\mathrm{BrO}$ observations, Atmos. Chem. Phys., 8, 7265-7271, doi:10.5194/acp-8-72652008, 2008. 
Feng, W., Chipperfield, M. P., Dorf, M., Pfeilsticker, K., and Ricaud, P.: Mid-latitude ozone changes: studies with a 3-D CTM forced by ERA-40 analyses, Atmos. Chem. Phys., 7, 2357-2369, doi:10.5194/acp-7-2357-2007, 2007.

Feng, W., Chipperfield, M. P., Dhomse, S., Monge-Sanz, B. M., Yang, X., Zhang, K., and Ramonet, M.: Evaluation of cloud convection and tracer transport in a three-dimensional chemical transport model, Atmos. Chem. Phys., 11, 5783-5803, doi:10.5194/acp-11-5783-2011, 2011.

Fueglistaler, S., Dessler, A. E., Dunkerton, T. J., Folkins, I., Fu, Q., and Mote, P. W.: Tropical tropopause layer, Reviews Geophys., 47, RG1004, doi:10.1029/2008RG000267, 2009.

Holtslag, A. and Boville, B.: Local versus nonlocal boundary-layer diffusion in a global climate model, J. Climate, 6, 1825-1842, 1993.

Hossaini, R., Chipperfield, M. P., Monge-Sanz, B. M., Richards, N. A. D., Atlas, E., and Blake, D. R.: Bromoform and dibromomethane in the tropics: a 3-D model study of chemistry and transport, Atmos. Chem. Phys., 10, 719-735, doi:10.5194/acp10-719-2010, 2010.

Hossaini, R., Chipperfield, M. P., Dhomse, S., Ordonez, C., Saiz-Lopez, A., Abraham, N. L., Archibald, A., Braesicke, P., Telford, P., Warwick, N., Yang, X., and Pyle, J.: Modelling future changes to the stratospheric source gas injection of biogenic bromocarbons, Geophys. Res. Lett., 39, L20813, doi:10.1029/2012GL053401, 2012a.

Hossaini, R., Chipperfield, M. P., Feng, W., Breider, T. J., Atlas, E., Montzka, S. A., Miller, B. R., Moore, F., and Elkins, J.: The contribution of natural and anthropogenic very short-lived species to stratospheric bromine, Atmos. Chem. Phys., 12, 371380, doi:10.5194/acp-12-371-2012, 2012b.

Kreycy, S., Camy-Peyret, C., Chipperfield, M. P., Dorf, M., Feng, W., Hossaini, R., Kritten, L., Werner, B., and Pfeilsticker, K.: Atmospheric test of the $J\left(\mathrm{BrONO}_{2}\right) / k \mathrm{BrO}+\mathrm{NO}_{2}$ ratio: implications for total stratospheric Bry and bromine-mediated ozone loss, Atmos. Chem. Phys., 13, 6263-6274, doi:10.5194/acp-136263-2013, 2013.

Krüger, K. and Quack, B.: Introduction to special issue: the TransBrom Sonne expedition in the tropical West Pacific, Atmos. Chem. Phys., 13, 9439-9446, doi:10.5194/acp-13-9439-2013, 2013.

Krüger, K., Tegtmeier, S., and Rex, M.: Variability of residence time in the Tropical Tropopause Layer during Northern Hemisphere winter, Atmos. Chem. Phys., 9, 6717-6725, doi:10.5194/acp-96717-2009, 2009.

Lary, D.: Gas phase atmospheric bromine photochemistry, J. Geophys. Res.-Atmos., 101, 1505-1516, doi:10.1029/95JD02463, 1996.

Lary, D. and Toumi, R.: Halogen-catalyzed methane oxidation, J. Geophys. Res.-Atmos., 102, 23421-23428, doi:10.1029/97JD00914, 1997.

Leedham, E. C., Hughes, C., Keng, F. S. L., Phang, S.-M., Malin, G., and Sturges, W. T.: Emission of atmospherically significant halocarbons by naturally occurring and farmed tropical macroalgae, Biogeosciences, 10, 3615-3633, doi:10.5194/bg-10-36152013, 2013.

Levine, J. G., Braesicke, P., Harris, N. R. P., Savage, N. H., and Pyle, J. A.: Pathways and timescales for troposphere-to-stratosphere transport via the tropical tropopause layer and their relevance for very short lived substances, JOURNAL OF Geophys. Res.Atmos., 112, D04308, doi:10.1029/2005JD006940, 2007.

Liang, Q., Stolarski, R. S., Kawa, S. R., Nielsen, J. E., Douglass, A. R., Rodriguez, J. M., Blake, D. R., Atlas, E. L., and Ott, L. E.: Finding the missing stratospheric Bry: a global modeling study of $\mathrm{CHBr}_{3}$ and $\mathrm{CH}_{2} \mathrm{Br}_{2}$, Atmos. Chem. Phys., 10, 2269-2286, doi:10.5194/acp-10-2269-2010, 2010.

Montzka, S. and Reimann, S.: Ozone-depleting substances (ODSs) and related chemicals, in: Scientific Assessment of Ozone Depletion: 2010, Global Ozone Research and Monitoring Project, Report No. 52, Chapt. 1, World Meteorological Organization, Geneva, 2011.

Montzka, S., Butler, J., Hall, B., Mondeel, D., and Elkins, J.: A decline in tropospheric organic bromine, Geophys. Res. Lett., 30, 1826, doi:10.1029/2003GL017745, 2003.

Ordóñez, C., Lamarque, J.-F., Tilmes, S., Kinnison, D. E., Atlas, E. L., Blake, D. R., Sousa Santos, G., Brasseur, G., and Saiz-Lopez, A.: Bromine and iodine chemistry in a global chemistry-climate model: description and evaluation of very short-lived oceanic sources, Atmos. Chem. Phys., 12, 1423-1447, doi:10.5194/acp12-1423-2012, 2012.

Patra, P. K., Houweling, S., Krol, M., Bousquet, P., Belikov, D., Bergmann, D., Bian, H., Cameron-Smith, P., Chipperfield, M. P., Corbin, K., Fortems-Cheiney, A., Fraser, A., Gloor, E., Hess, P., Ito, A., Kawa, S. R., Law, R. M., Loh, Z., Maksyutov, S., Meng, L., Palmer, P. I., Prinn, R. G., Rigby, M., Saito, R., and Wilson, C.: TransCom model simulations of $\mathrm{CH}_{4}$ and related species: linking transport, surface flux and chemical loss with $\mathrm{CH}_{4}$ variability in the troposphere and lower stratosphere, Atmos. Chem. Phys., 11, 12813-12837, doi:10.5194/acp-11-12813-2011, 2011.

Pfeilsticker, K. and the SHIVA consortium: Overview on the project SHIVA (Stratospheric Ozone: Halogen Impacts in a Varying Atmosphere): Achievements and key results, in preparation, 2013.

Pfeilsticker, K., Sturges, W., Bosch, H., Camy-Peyret, C., Chipperfield, M., Engel, A., Fitzenberger, R., Muller, M., Payan, S., and Sinnhuber, B.: Lower stratospheric organic and inorganic bromine budget for the Arctic winter 1998/99, Geophys. Res. Lett., 27, 3305-3308, doi:10.1029/2000GL011650, 2000.

Prather, M.: Numerical advection by conservation of 2ndorder moments, J. Geophys. Res.-Atmos., 91, 6671-6681, doi:10.1029/JD091iD06p06671, 1986.

Pyle, J. A., Ashfold, M. J., Harris, N. R. P., Robinson, A. D., Warwick, N. J., Carver, G. D., Gostlow, B., O’Brien, L. M., Manning, A. J., Phang, S. M., Yong, S. E., Leong, K. P., Ung, E. H., and Ong, S.: Bromoform in the tropical boundary layer of the Maritime Continent during OP3, Atmos. Chem. Phys., 11, 529-542, doi:10.5194/acp-11-529-2011, 2011.

Quack, B. and Wallace, D.: Air-sea flux of bromoform: Controls, rates, and implications, Global Biogeochem. Cy., 17, 1023, doi:10.1029/2002GB001890, 2003.

Read, K. A., Mahajan, A. S., Carpenter, L. J., Evans, M. J., Faria, B. V. E., Heard, D. E., Hopkins, J. R., Lee, J. D., Moller, S. J., Lewis, A. C., Mendes, L., McQuaid, J. B., Oetjen, H., Saiz-Lopez, A., Pilling, M. J., and Plane, J. M. C.: Extensive halogen-mediated ozone destruction over the tropical Atlantic Ocean, Nature, 453, 1232-1235, doi:10.1038/nature07035, 2008.

Saiz-Lopez, A. and von Glasow, R.: Reactive halogen chemistry in the troposphere, Chem. Soc. Rev., 41, 6448-6472, doi:10.1039/c2cs35208g, 2012. 
Saiz-Lopez, A., Lamarque, J.-F., Kinnison, D. E., Tilmes, S., Ordóñez, C., Orlando, J. J., Conley, A. J., Plane, J. M. C., Mahajan, A. S., Sousa Santos, G., Atlas, E. L., Blake, D. R., Sander, S. P., Schauffler, S., Thompson, A. M., and Brasseur, G.: Estimating the climate significance of halogen-driven ozone loss in the tropical marine troposphere, Atmos. Chem. Phys., 12, 3939-3949, doi:10.5194/acp-12-3939-2012, 2012.

Sala, S., Bönisch, H., Keber, T., and Engel, A.: A Budget of total organic bromine from airborne VSLS measurements during SHIVA, in preparation, 2013.

Salawitch, R., Weisenstein, D., Kovalenko, L., Sioris, C., Wennberg, P., Chance, K., Ko, M., and McLinden, C.: Sensitivity of ozone to bromine in the lower stratosphere, Geophys. Res. Lett., 32, L05811, doi:10.1029/2004GL021504, 2005.

Salawitch, R. J., Canty, T., Kurosu, T., Chance, K., Liang, Q., da Silva, A., Pawson, S., Nielsen, J. E., Rodriguez, J. M., Bhartia, P. K., Liu, X., Huey, L. G., Liao, J., Stickel, R. E., Tanner, D. J., Dibb, J. E., Simpson, W. R., Donohoue, D., Weinheimer, A., Flocke, F., Knapp, D., Montzka, D., Neuman, J. A., Nowak, J. B., Ryerson, T. B., Oltmans, S., Blake, D. R., Atlas, E. L., Kinnison, D. E., Tilmes, S., Pan, L. L., Hendrick, F., Van Roozendael, M., Kreher, K., Johnston, P. V., Gao, R. S., Johnson, B., Bui, T. P., Chen, G., Pierce, R. B., Crawford, J. H., and Jacob, D. J.: A new interpretation of total column BrO during Arctic spring, Geophys. Res. Lett., 37, L21805, doi:10.1029/2010GL043798, 2010.

Sander, S., Friedl, R., Barker, J., Golden, D., Kurylo, M., Wine, P., Abbatt, J., Burkholder, J., Kolb, C., Moortgat, G., Huie, R., and Orkin, V.: Chemical Kinetics and Photochemical Data for Use in Atmospheric Studies, Evaluation Number 17, JPL Publication 10-6, Jet Propulsion Laboratory, 2011.

Schofield, R., Fueglistaler, S., Wohltmann, I., and Rex, M.: Sensitivity of stratospheric Bry to uncertainties in very short lived substance emissions and atmospheric transport, Atmos. Chem. Phys., 11, 1379-1392, doi:10.5194/acp-11-1379-2011, 2011.

Sioris, C. E., Kovalenko, L. J., McLinden, C. A., Salawitch, R. J., Van Roozendael, M., Goutail, F., Dorf, M., Pfeilsticker, K., Chance, K., von Savigny, C., Liu, X., Kurosu, T. P., Pommereau, J. P., Boesch, H., and Frerick, J.: Latitudinal and vertical distribution of bromine monoxide in the lower stratosphere from Scanning Imaging Absorption Spectrometer for Atmospheric Chartography limb scattering measurements, J. Geophys. Res.Atmos., 111, D14301, doi:10.1029/2005JD006479, 2006.

Solomon, S.: Stratospheric ozone depletion: a review of concepts and history, Rev. Geophys., 37, 275-316, 1999.

Stockwell, D. and Chipperfield, M.: A tropospheric chemicaltransport model: Development and validation of the model transport schemes, Q. J. Roy. Meteorol. Soc., 125, 1747-1783, doi:10.1256/smsqj.55713, 1999.

Sturges, W., Oram, D., Carpenter, L., Penkett, S., and Engel, A.: Bromoform as a source of stratospheric bromine, Geophys. Res. Lett., 27, 2081-2084, doi:10.1029/2000GL011444, 2000.

Swanson, A., Davis, D., Arimoto, R., Robert, P., Atlas, E., Flocke, F., Meinardi, S., Rowland, F., and Blake, D.: Organic trace gases of oceanic origin observed at South Pole during ISCAT 2000, Atmos. Environ., 38, 5463-5472, doi:10.1016/j.atmosenv.2004.03.072, 2004.
Tegtmeier, S., Krüger, K., Quack, B., Atlas, E. L., Pisso, I., Stohl, A., and Yang, X.: Emission and transport of bromocarbons: from the West Pacific ocean into the stratosphere, Atmos. Chem. Phys., 12, 10633-10648, doi:10.5194/acp-12-10633-2012, 2012.

Tiedtke, M.: A comprehensive mass flux scheme for cumulus parameterization in large-scale models, Mon. Weather Rev., 117, 1779-1800, doi:10.1175/15200493(1989)117<1779:ACMFSF>2.0.CO;2, 1989.

von Glasow, R., von Kuhlmann, R., Lawrence, M. G., Platt, U., and Crutzen, P. J.: Impact of reactive bromine chemistry in the troposphere, Atmos. Chem. Phys., 4, 2481-2497, doi:10.5194/acp-42481-2004, 2004.

Warwick, N. J., Pyle, J. A., Carver, G. D., Yang, X., Savage, N. H., O'Connor, F. M., and Cox, R. A.: Global modeling of biogenic bromocarbons, J. Geophys. Res.-Atmos., 111, D24305, doi:10.1029/2006JD007264, 2006.

WMO: Scientific Assessment of Ozone Depletion: 2006, Global Ozone Research and Monitoring Project, Report No. 50, World Meteorological Organization, Geneva, Switzerland, 2007.

WMO: Scientific Assessment of Ozone Depletion: 2010, Global Ozone Research and Monitoring Project, Report No. 52, World Meteorological Organization, Geneva, Switzerland, 2011.

Wofsy, S. C., Team, H. S., Team, C. M., and Team, S.: HIAPER Pole-to-Pole Observations (HIPPO): fine-grained, globalscale measurements of climatically important atmospheric gases and aerosols, Philos. T. Roy. Soc. A, 369, 2073-2086, doi:10.1098/rsta.2010.0313, 2011.

Worton, D. R., Mills, G. P., Oram, D. E., and Sturges, W. T.: Gas chromatography negative ion chemical ionization mass spectrometry: Application to the detection of alkyl nitrates and halocarbons in the atmosphere, J. Chromatogr. A, 1201, 112-119, doi:10.1016/j.chroma.2008.06.019, 2008.

Yang, X., Cox, R., Warwick, N., Pyle, J., Carver, G., O’Connor, F., and Savage, N.: Tropospheric bromine chemistry and its impacts on ozone: A model study, JOURNAL OF Geophys. Res.-Atmos., 110, D23311, doi:10.1029/2005JD006244, 2005.

Yokouchi, Y., Barrie, L., Toom, D., and Akimoto, H.: The seasonal variation of selected natural and anthropogenic halocarbons in the Arctic troposphere, Atmos. Environ., 30, 1723-1727, doi:10.1016/1352-2310(95)00393-2, 1996.

Ziska, F., Quack, B., Abrahamsson, K., Archer, S. D., Atlas, E., Bell, T., Butler, J. H., Carpenter, L. J., Jones, C. E., Harris, N. R. P., Hepach, H., Heumann, K. G., Hughes, C., Kuss, J., Krüger, K., Liss, P., Moore, R. M., Orlikowska, A., Raimund, S., Reeves, C. E., Reifenhäuser, W., Robinson, A. D., Schall, C., Tanhua, T., Tegtmeier, S., Turner, S., Wang, L., Wallace, D., Williams, J., Yamamoto, H., Yvon-Lewis, S., and Yokouchi, Y.: Global sea-toair flux climatology for bromoform, dibromomethane and methyl iodide, Atmos. Chem. Phys., 13, 8915-8934, doi:10.5194/acp13-8915-2013, 2013. 